\title{
THE SCANDINAVIAN FANTASY: \\ THE SOURCES OF INTERGENERATIONAL MOBILITY IN DENMARK AND THE U.S.
}

\author{
Rasmus Landers $\emptyset$ \\ James J. Heckman \\ Working Paper 22465 \\ http://www.nber.org/papers/w22465 \\ NATIONAL BUREAU OF ECONOMIC RESEARCH \\ 1050 Massachusetts Avenue \\ Cambridge, MA 02138 \\ July 2016
}

This paper was presented at a Conference on Social Mobility held at the University of Chicago on November 5th, 2014, under the title "The Role of Income and Credit Constraints in Human Development' Part II." We thank Linor Kiknadze for very helpful research assistance. We thank Magne Mogstad and the participants in the conference for thoughtful comments. We also received helpful comments at a January 2015 seminar at the Norwegian School of Economics, and seminars at the University of Copenhagen, Aarhus University, SOFI (Stockholm), INET Paris (April 2015), and Copenhagen Education Network. We are especially grateful to Roger Bivand, Sam Bowles, Juanna Joensen, Øivind Anti Nilsen, Kjell Salvanes, Agnar Sandmo, Erik Sørensen, Torben Tranæs, Anders Björklund, and Matthew Lindquist. We have received helpful comments on this draft of the paper from Juanna Schrøter Joensen, Rich Neimand, Matt Tauzer, and Ingvil Gaarder. This research was supported in part by: the Pritzker Children's Initiative; the Buffett Early Childhood Fund; NIH grants NICHD R37HD065072, NICHD R01HD054702, and NIA R24AG048081; an anonymous funder; The Rockwool Foundation; Successful Pathways from School to Work, an initiative of the University of Chicago's Committee on Education and funded by the Hymen Milgrom Supporting Organization; the Human Capital and Economic Opportunity Global Working Group, an initiative of the Center for the Economics of Human Development and funded by the Institute for New Economic Thinking; and the American Bar Foundation. The views expressed in this paper are solely those of the authors and do not necessarily represent those of the funders or the official views of the National Institutes of Health. The Web Appendix for this paper is https://heckman.uchicago.edu/ mobility_denmark_us. The views expressed herein are those of the authors and do not necessarily reflect the views of the National Bureau of Economic Research.

NBER working papers are circulated for discussion and comment purposes. They have not been peerreviewed or been subject to the review by the NBER Board of Directors that accompanies official NBER publications.

(C) 2016 by Rasmus Landers $\varnothing$ and James J. Heckman. All rights reserved. Short sections of text, not to exceed two paragraphs, may be quoted without explicit permission provided that full credit, including (C) notice, is given to the source. 
The Scandinavian Fantasy: The Sources of Intergenerational Mobility in Denmark and the U.S.

Rasmus Landers $\emptyset$ and James J. Heckman

NBER Working Paper No. 22465

July 2016

JEL No. I24,I28,I32,P51

\section{ABSTRACT}

This paper examines the sources of differences in social mobility between the U.S. and Denmark. Measured by income mobility, Denmark is a more mobile society, but not when measured by educational mobility. There are pronounced nonlinearities in income and educational mobility in both countries. Greater Danish income mobility is largely a consequence of redistributional tax, transfer, and wage compression policies. While Danish social policies for children produce more favorable cognitive test scores for disadvantaged children, these do not translate into more favorable educational outcomes, partly because of disincentives to acquire education arising from the redistributional policies that increase income mobility.

Rasmus Landers $\varnothing$

Rockwool Foundation Research Unit

Solvgade 10

DK 1307, Copenhagen

Denmark

$\mathrm{rl} @ \mathrm{rff} . \mathrm{dk}$

James J. Heckman

Department of Economics

The University of Chicago

1126 E. 59th Street

Chicago, IL 60637

and IZA

and also NBER

jjh@uchicago.edu

A data appendix is available at http://www.nber.org/data-appendix/w22465 
"The American Dream is now spoken with a Scandinavian accent." -

Washington Post (2014)

\section{Introduction}

Policy analysts around the world point to Scandinavia as a model for reducing inequality and promoting intergenerational mobility (see, e.g., Baily, 2016). By conventional measures, social mobility by income is much higher there than in the U.S.

This paper uses rich Danish data to explore the sources of these differences in social mobility. By all accounts, Denmark is a prototypical Scandinavian welfare state. Lessons learned from Danish data apply to Scandinavia, more generally.

Our investigation reveals some surprises and apparent contradictions. The literature on Danish social mobility by income is surprisingly sparse and uses only a limited number of measures of income. One contribution of this paper is to demonstrate that the choice of the measure of income used matters greatly in determining the relative social mobility of the U.S. and Denmark.

The standard measure of intergenerational mobility is based on the intergenerational elasticity (IGE): a regression coefficient showing the percentage change in a child's income associated with a percentage change in parental income. We show that estimated IGEs depend greatly on the measure of income used and that estimated IGEs vary with the level of income. U.S. social mobility is low (absolutely and compared to Denmark) for children from high income families.

Popular discussions of the benefits of the Scandinavian welfare state point to its generous support of child care and education relative to the U.S. as major determinants of its greater social mobility. In Denmark, college tuition is free, there is ready access to child care, pregnancy 
leave policy is generous, and there is virtually universal free pre-K. Yet despite these stark policy differences, the influence of family background on educational attainment is surprisingly similar in the two countries. Levels of intergenerational educational mobility are about the same. At higher levels of family income, educational mobility is lower in both countries.

In both countries, cognitive and non-cognitive skills acquired by age 15 are more important for predicting educational attainment than parental income. The more child-generous Danish welfare state produces much more favorable distribution of cognitive skills for disadvantaged Danish children compared to their counterparts in the U.S. The similarity of the influence of family background on educational attainment in the two countries, despite the most favorable distribution of test scores for Danish disadvantaged children, arises in part from the compression of the wage scale and the generous levels of social benefits that discourage Danish children from pursuing further schooling. In addition, the generosity of the Danish welfare state does not prevent sorting of children into neighborhoods and schools on the basis of family background, which appears to benefit the more advantaged.

Scandinavia invests heavily in child development and boosts the test scores of the disadvantaged. It then undoes these beneficial effects by providing weak labor market incentives. Better incentives to acquire skills would boost Danish educational mobility. Stated differently, the greater incentives to acquire education in the U.S. labor market tend to offset its less favorable investments in the cognitive skills of disadvantaged children. In addition, while the Danish welfare state promotes equality of opportunity compared to the U.S., many barriers remain. There are large skill gaps between the children of the advantaged and the children of the disadvantaged, during early and late childhood. Residential sorting across neighborhoods and schools is strong.

This paper proceeds in the following way. Section 2 analyzes income mobility in Denmark and the U.S. We examine the sensitivity of estimated income intergenerational elasticities 
(IGE) to alternative measures of income. We examine the sources of differences in income mobility. We also report nonparametric estimates of income mobility. Section 3 examines the relationship between schooling attainment, measures of family financial resources, cognitive and non-cognitive skills of children at age 15, family background (education and home environment), and measures of schooling quality. We report surprisingly similar effects of family influence on educational attainment in both societies. We show a link between welfare benefits and educational attainment in Denmark. We discuss the role of neighborhood sorting on child educational attainment. Section 4 qualifies our analysis. Section 5 concludes.

\section{Income Mobility}

This section explores alternative measures of intergenerational income mobility. Different measures of income convey very different impressions of social mobility. We show how the levels of transfers, the mapping of education to income, the levels and progressivity of taxation, and income inequality differ between the U.S. and Denmark. All four factors affect estimates of income mobility.

We report estimates of Nonlinear Intergenerational Income Elasticities (NL-IGE) for both countries. We find different patterns depending on which income measure we consider. Differences favoring Denmark appear at the lowest and the highest levels of income.

\subsection{Data}

U.S. data. We use two U.S. data sources. We use PSID data for our main analysis of intergenerational income mobility. We measure parental income using a 9-year average from 
the child's 7 th to 15 th year.11 Child income is measured as income at ages $34-41$ down to ages ranging from 30-35 for the 1972 to 1978 birth cohorts, respectively. In our main analysis we only consider individuals with positive incomes. Web Appendix F gives further details.

As the sample size for the PSID data is small (relative to the Danish data), we use the March Current Population Survey (CPS) (1968-2014) from Integrated Public Use Microdata Series (IPUMS) ${ }^{2}$ when we use U.S. income distributions in the analysis. The sample consists of civilian, non-institutionalized citizens. We use parents in 1987 and individuals age 36-38 in 2011.

Danish data. ${ }^{3}$ For Denmark we use the full population register data on the entire cohorts born in 1973-1975. We discard individuals who migrate (or whose parents migrate), individuals for whom we have no identification of the father or mother (around $2 \%$ ), and individuals with negative incomes (average over the period where we measure income). Parental income is measured as a 9-year average from when the child is $7-15$ years of age and the child's income is measured at ages 35-37, 36-38, and 37-39 for the 1975, 1974, and 1973 cohorts, respectively. The full sample size is 166,359 , and once we restrict to positive incomes the sample is reduced to 149,190 individual parent-child matches. ${ }^{4}$

Table A23 provides the definitions of the various income measures we consider. Table A1 in the Web Appendix summarizes income levels for the U.S. and Denmark by different quantiles and income measures, and Figure A1 depicts the distributions. The table and figure show that incomes in Denmark are more compressed than incomes in the U.S. There is a large low-income

\footnotetext{
${ }^{1}$ Throughout the analysis we use total parental income and do not adjust for differences in household size by the number of siblings.

${ }^{2}$ All calculations are weighted by CPS sampling weights and are deflated using PCE deflator.

${ }^{3}$ Throughout the paper we use a PPP adjusted exchange rate of $\$ 100$ to DKK 776 (as reported by the OECD).

${ }^{4}$ Table A2 presents results where we sample cohorts in the Danish register data with the same distribution as observed in the PSID data, and where we sample the number of observations in each cohort as observed in the PSID data. The results do not differ significantly or qualitatively from our main results which we will present in Table 1
} 
group in the U.S. that almost does not exist in Denmark Aaberge et al., 2002, Corak, 2013 , Forslund and Krueger, 1997) 5 In the next section, we show that cross-sectional differences in income distributions between Denmark and the U.S. are an important source of higher income mobility in Denmark than in the U.S.

\subsection{Linear Intergenerational Income Elasticities}

A large literature investigates the association between parents' and children's income 6 The modal statistic used to study income mobility is the intergenerational elasticity (IGE) of income $\beta^{I G E}:$

$$
\ln \left(Y^{C}\right)=\alpha+\beta^{I G E} \ln \left(Y^{P}\right)
$$

The father/son or parent/child IGE is generally found to be much higher in the U.S. than in Denmark. Estimates generally lie between 0.3 and 0.5 in the U.S. and around 0.1 to 0.2 in Denmark (Björklund and Jäntti, 2011; Blanden, 2013; Mazumder, 2005, Solon, 2002). There is a similar range for rank-rank associations. Boserup et al. (2013) and Chetty et al. (2014) estimate this to be 0.18 in Denmark and 0.34 in the U.S., respectively. Based on these estimates of the income IGE, Scandinavia is portrayed as a land of opportunity.7

Cross-country differences in estimated IGEs of income can arise for a multitude of reasons that we attempt to capture using different income measures. One measure proxies transmission of total individual income potential with wage earnings, capital income, and profits.

\footnotetext{
${ }^{5}$ See Section B in the Web Appendix. Freeman et al. (2010) discuss a broad range of likely causes and consequences of wage-compression for the Swedish welfare-state. See also Aaberge et al. (2000), Pedersen and Smith (2000), and Tranæs (2006), who provide similar evidence from Denmark.

${ }^{\circ}$ See, e.g., Blanden (2013), Corak (2006), and Solon $(2002)$ for reviews of the literature.

${ }^{7}$ See Table 5 in the Appendix to this text for a summary of previous IGE estimates for Denmark (comprehensive) and the U.S. (selected).
} 
Another proxies transmission of total income including public transfers. 8 A third measure introduces the effects of the progressivity of the taxation on income mobility. A fourth measure, wage earnings, proxies intergenerational transmission of earnings-potential rewarded in labor market — differences arise, in part, from differences in returns to education.

A further source of differences in estimated IGEs arises from differences in levels and trends in cross-sectional income inequality ${ }^{9}$ We put this issue aside for now, and investigate it in the next subsection.

Table 1 shows estimated intergenerational income elasticities for similar income measures in Denmark and the U.S. The odd-numbered columns report estimates for Denmark. The even-numbered columns report the corresponding estimates for the U.S.

Column 1 shows that the estimated IGE based on gross income, excluding public transfers, is 0.352 for Denmark. This estimate is much higher than estimates reported in the literature that use wage earnings, earnings, or income including public transfers. The corresponding estimate for the U.S. is 0.312 . The difference between the two estimates is not statistically significant. The third and fourth columns show that the estimated IGE for Denmark drops by around $20 \%$ to 0.271 when public transfers are included in the measure of income. This decrease illustrates the important role of redistribution in Denmark. For the U.S., the corresponding estimate jumps to 0.446, bringing us close to the estimate reported in Solon (1992) and Chetty et al. (2014) (see Table 5 in the Appendix to this text). Comparing the estimate in column 3 in Table 1 to that of column 9 in the same table, we see that adding taxation reduces the Danish IGE estimate further. Unfortunately, we do not have the data required to estimate the

\footnotetext{
${ }^{8}$ But not the impact of in-kind transfers.

${ }^{9}$ The previous literature investigating social mobility has long addressed some of the issues. One early example is Solon (1992).
} 
corresponding IGE for the U.S.10

When we focus on wage earnings alone in columns 5 and 6 , the estimated IGE for Denmark drops dramatically to 0.081 , while the corresponding U.S. estimate is 0.289 . Finally, adding public transfers to wage earnings results in an even larger gap between the two countries. For wage earnings plus public transfers, the Danish IGE is 0.063 while the U.S. is 0.41911

Our estimates for Denmark do not contradict the findings of the previous literature. Rather, they enrich our understanding of them. Measured by income potential (column 1 and 2), we find that intergenerational mobility in Denmark is not significantly different from intergenerational mobility in the U.S. When we account for public transfers, estimates for the two countries diverge. Income mobility by this measure is substantially higher in Denmark than in the U.S. When we consider wage earnings alone or wage earnings inclusive of public transfers, we obtain estimates for Denmark reported in the previous literature with estimated IGEs around 0.1 .

\footnotetext{
${ }^{10}$ Table A3 in the Web Appendix shows IGE estimates while controlling for child's highest completed grade. The table shows that controlling for own education reduces the IGE estimates by approximately $1 / 3$ relative to the unadjusted estimates presented in Table 1. Yet the overall differences between income measures and countries remain unchanged. IGE estimates are similar for Denmark and the U.S. for gross income excluding transfers, but diverge for other income measures. In addition, it is evident from the table that the coefficients for child's highest completed grade on income are larger in the U.S. than in Denmark. Furthermore, the coefficients for child's highest completed grade for Denmark decrease substantially when we consider income measures including transfers or post-tax income, whereas they are unaffected by the inclusion of transfers for the U.S.

${ }^{11}$ In Table A4 in the Web Appendix, we show the corresponding IGE estimates while controlling for parents' education. The estimated elasticities decrease by $25-30 \%$, but we find no sign of any patterns or cross-country difference that is not present for the unadjusted IGE estimates in Table 1.
} 
Table 1: IGE estimates with different income measures Denmark and the U.S.

\begin{tabular}{|c|c|c|c|c|c|c|c|c|c|}
\hline & \multicolumn{2}{|c|}{$\begin{array}{l}\text { Gross income excl. } \\
\text { public transfers }\end{array}$} & \multicolumn{2}{|c|}{$\begin{array}{l}\text { Gross income incl. } \\
\text { public transfers }\end{array}$} & \multicolumn{2}{|c|}{ Wage earnings } & \multicolumn{2}{|c|}{$\begin{array}{l}\text { Wage earnings and } \\
\text { public transfers }\end{array}$} & \multirow{3}{*}{$\begin{array}{c}\text { Net-of-tax total } \\
\text { gross income } \\
(9) \\
\text { Denmark }\end{array}$} \\
\hline & (1) & (2) & (3) & (4) & $(5)$ & (6) & (7) & (8) & \\
\hline & Denmark & U.S. & Denmark & $U . S$ & Denmark & U.S. & Denmark & U.S. & \\
\hline & $\begin{array}{c}0.352^{* * *} \\
(0.004)\end{array}$ & $\begin{array}{c}0.312^{* * *} \\
(0.055)\end{array}$ & $\begin{array}{c}0.271^{* * *} \\
(0.003)\end{array}$ & $\begin{array}{c}0.446^{* * *} \\
(0.054)\end{array}$ & $\begin{array}{c}0.083^{* * *} \\
(0.003)\end{array}$ & $\begin{array}{c}0.289^{* * *} \\
(0.044)\end{array}$ & $\begin{array}{c}0.063^{* * *} \\
(0.003)\end{array}$ & $\begin{array}{c}0.419^{* * *} \\
(0.058)\end{array}$ & $\begin{array}{c}0.221^{* * *} \\
(0.003)\end{array}$ \\
\hline Observations & 149,190 & 621 & 149,190 & 621 & 149,190 & 621 & 149,190 & 621 & 149,190 \\
\hline
\end{tabular}

Note: Table shows coefficients $\left(\beta^{I G E}\right)$ and standard errors from regressions of child log income on parents' log income for Denmark and the U.S. For Denmark, we use full population register data for children born in 1973-1975, and for the U.S. we use PSID data children born in 1972-1978. For Denmark, parental income is measured as a 9 year average from the child's 7 th to 15 th year and the child's income is measured at ages 35-37, 36-38, and 37-39 for the 1975, 1974, and 1973 cohorts, respectively. For the U.S., parental income is measured as a 9 year average from the child's 7 th to 15 th year and the child's income is measured as last year income at ages 34-41, 33-40, 32-39, 31-38, 30-37, 30-36, and 30-35 for the 1972, 1973, 1974, 1975, 1976, 1977 and 1978 cohorts, respectively.

Total gross income excl. public transfers

1 Denmark: All taxable income including wage earnings, profits from own business, capital income, and foreign income excluding all public transfers (both taxable and non-taxable).

2 U.S.: All taxable income including earnings (payroll income from all sources, farm income, and the labor portion of business income), asset income (such as rent income, dividends, interest, income from trust and royalties, and asset income from business), and private transfers (such as income from alimony, child support, and help from relatives and others).

Total gross income incl. public transfers

3 Denmark: All taxable income including wage earnings, public transfers, profits from own business, capital income, and foreign income.

4 U.S.: All taxable income including earnings, asset income, private transfers and public transfers (such as social security income, SSI, TANF, ETC, other welfare income, retirement, pension, unemployment, and workers compensation).

Wage earnings

5 Denmark: Taxable wage earnings and fringes, labor portion of business income, and non-taxable earnings, severance pay, and stock-options.

6 U.S.: Payroll income from all sources (such as wages and salaries, bonus, overtime income, tips, commissions, professional practice, market gardening, additional job income, and other labor income), farm income, and labor portion of business income. Wage and public transfers

7 Denmark: Taxable wage earnings and fringes, labor portion of business income, and non-taxable earnings, severance pay, and stock-options, plus taxable and non-taxable public transfers (social assistance, unemployment benefits, labor market leave, sick leave assistance, labor market activation, child-benefits, education grants, housing support, early retirement pension, disability pension, and retirement pension).

8 U.S.: Payroll income from all sources, farm income, labor portion of business income, and public transfers.

Net-of-tax total gross income

9 Denmark: Total gross income minus all final income taxes paid in given year. We do not have information on individual net-of-tax income from the PSID. 
One should generally interpret cross-country differences with great caution. There is no single best measure of the IGE. We do not claim that we have shown that levels of income mobility in the U.S. and Denmark are alike or different. The conclusion from this analysis is that accounting for transfers, wage compression, returns to education, and progressive income taxation explains a substantial portion of the Denmark-U.S. difference in associations between children's and parents' income.

In addition, several measurement problems discussed in the previous literature (see, e.g., Solon, 2004) might also affect estimated IGEs. Imputing zeros with an arbitrary value affects estimates. Censoring may also produce biased results, for example, by leaving out the long-term unemployed from the analysis 12 Table $\mathrm{A} 5$ in the Web Appendix reports the corresponding estimates of Table 1 when imputing zero incomes with $\$ 1,000$. The table shows that estimated IGEs change for income categories that include many zeros (gross income excluding transfers and wage earnings) ${ }^{13}$ Nevertheless, the overall patterns from Table 1 remain unchanged for Denmark. For the U.S., the PSID data is, however, much more sensitive to the inclusion of zero and non-reported incomes. In order to obviate the problems with zero income, analyses estimating relationships between child and parents' ranks in their respective income distributions ${ }^{14}$ have recently been used (see Dahl and DeLeire, 2008 and Chetty et al. 2014). We do not report results for rank-rank estimates in the main text and refer readers to

\footnotetext{
${ }^{12}$ Additional measurement problems include life cycle bias and measurement error from year-to-year variation in income. We attempt to avoid these potential biases by considering parental and child income measured as averages over several years (permanent income) and by measuring children's income when they are in their late 30s.

${ }^{13}$ For Denmark, estimated IGEs increase the smaller number used to make the imputation. When we use $\$ 1,000$, the estimated IGE for gross income excluding transfers is 0.49 , and when we use $\$ 1$ it increases to around 0.6 .

${ }^{14} \beta^{R R}(\operatorname{rank}-\operatorname{rank})=\operatorname{Corr}\left(R\left(Y^{P}\right), R\left(Y^{C}\right)\right)$ where $R(*)$ denotes children's and parents' rank in their respective distributions. While $\beta^{R R}$ is scale invariant in income, $\beta^{I G E}$ is not. The link between the two measures depends on the underlying distributions (see Trivedi and Zimmer, 2007).
} 
the Web Appendix. 15 16

\subsection{The Role of Inequality in Shaping the IGE}

The cross-country correlation between income mobility and income inequality has received a lot of attention in the past decade (Corak, 2006). Krueger (2012) calls this the Great Gatsby curve. In this subsection, we examine the mechanical relationship between estimated IGE and changes in inequality across generations. It follows the definition of the IGE,

$$
\beta^{I G E}=\operatorname{corr}\left(\ln \left(Y^{C}\right), \ln \left(Y^{P}\right) \frac{\operatorname{sd}\left(\ln \left(Y^{C}\right)\right)}{\operatorname{sd}\left(\ln \left(Y^{P}\right)\right)},\right.
$$

that increase in inequality from one generation to the next amplifies the estimate without affecting mobility measured by correlation coefficients. Hence, differences in inequality between

\footnotetext{
${ }^{15}$ Table A6 in the Web Appendix replicates this analysis for rank-rank regressions. The findings are qualitatively similar. For total gross income excluding transfers, the Danish estimates are close to the U.S. levels reported by Chetty et al. (2014. Table 1, line 7, column 1). When we consider wage earnings alone and/or include public transfers, large cross differences arise (compare Danish levels to Chetty et al., 2014. Table 1, line 8, column 1).

${ }^{16}$ Rank-rank analyses do not solve the issues that the researcher faces when using log income. We refer the reader to Web Appendix C for discussion. Web Appendix C presents further results on two of the additional issues often discussed in the previous literature on income mobility. For a recent review, see Black and Devereux (2011). The first issue is life cycle bias, i.e., that associations between children's and parents' income will be 'understated' if children's income is measured early in their working career, where yearly earnings do not reflect life-time earnings. We show that the rank-rank slopes for Denmark do not stabilize until the child's income is measured during his/her late 30s (see Figure A42 in the Web Appendix and Nybom and Stuhler, 2015 for similar evidence from Sweden). We also illustrate that measuring parental income earlier in the child's life reduces the rank-rank slopes. (In Denmark, measuring children's income during their early 20s actually results in negative coefficients.) The second issue is attenuation bias (measurement error bias) that stems from the noise arising from including too few years of income data (Solon, 1992). In the Danish data, this can be much larger than the levels reported in Chetty et al. (2014). When we measure parental income when the child is below 10 years of age and add income data from subsequent years to the analysis, the differences in rank-rank slopes based on 1 and 5 years of data, respectively, range from $12-32 \%$ depending on which income measure is used (see Figure A43). However, when we use income measured during the child's late teens and add data from preceding years, the corresponding 1-5 year differences are around $0-3 \%$ in accord with Chetty et al.s analysis.
} 
generations and countries may generate differences in perceived income mobility ${ }^{17}$

Table 2 shows how differences in variances drive estimates. The table shows the regression coefficients from Table 1 together with the correlation and intergenerational ratio of standard deviations below each coefficient. The table shows that, although not statistically significantly different, the intergenerational correlation for gross income excluding transfers in the U.S. is above its Danish counterpart. It is the ratio of standard deviations that drives the Danish IGE to levels above the U.S. When public transfers are included in gross income, the correlation and ratio increase in the U.S., while in Denmark the ratio decreases and correlation is roughly unchanged. These results also emphasize that transfers are more progressive and constitute a larger fraction of income in Denmark compared to the U.S. Furthermore, the table shows that the large increase in the estimated IGE for the U.S. when public transfers are included, partly arises because transfers reduce inequality in parents' income while inequality in children's income is largely unaffected.18 When we focus on wage earnings alone, the correlation in Denmark drops from a level of 0.21 to 0.08 , whereas in the U.S. the intergenerational correlation remains at an unchanged level ${ }^{19}$ Table A5 in the Web Appendix presents a corresponding analysis imputing zero incomes with $\$ 1,000$. The main difference for Denmark is that intergenerational correlations for gross income excluding transfers and wage earnings increase to 0.246 and 0.118 , respectively, while the correlations for the remaining

\footnotetext{
${ }^{17}$ In a similar vein, one might question how differential trends in educational inequality affect comparisons across countries with high rates of high school and college degrees in earlier generations, as in the U.S., and countries where high school and college degrees become modal only over the past 30-50 years, as in Denmark and Norway. This remains an open question.

${ }^{18}$ This is also shown in Figure A24 in the Web Appendix, where we use CPS data for the U.S. and register data for Denmark to plot average wage earnings and wage earnings plus transfers in the two countries across different educational levels for the cohorts born 1947-1978.

${ }^{19}$ In Tables A8 A12 in the Web Appendix we report the intergenerational correlations and standard deviations of all major income components for Denmark. The tables show that the increased ratio of standard deviations from wage earnings to gross income stems from capital income and profits from own businesses. The ratio of standard deviations changes drastically for gross income because the covariance between wage earnings and profits is negative for parents and zero for children, thus reducing the overall variance of parents' income relative to children's income.
} 
incomes measure remain largely unaffected. Hence, including individuals with zero incomes, there is a substantial reduction in the intergenerational correlation when we add transfers to gross income in Denmark.

Table 2: Intergenerational correlations and inequality for different income measures Denmark and the U.S.

\begin{tabular}{|c|c|c|c|c|c|c|c|c|}
\hline & \multicolumn{2}{|c|}{$\begin{array}{l}\text { Gross income excl. } \\
\text { public transfers }\end{array}$} & \multicolumn{2}{|c|}{$\begin{array}{l}\text { Gross income incl. } \\
\text { public transfers }\end{array}$} & \multicolumn{2}{|c|}{ Wage earnings } & \multicolumn{2}{|c|}{$\begin{array}{l}\text { Wage earnings and } \\
\text { public transfers }\end{array}$} \\
\hline & (1) & $(2)$ & (3) & (4) & $(5)$ & (6) & (7) & (8) \\
\hline & Denmark & U.S. & Denmark & $U . S$. & Denmark & U.S. & Denmark & U.S. \\
\hline$\beta^{I G E}$ & $0.352^{* * *}$ & $0.312^{* * *}$ & $0.271^{* * *}$ & $0.446^{* * *}$ & $0.083^{* * *}$ & $0.289^{* * *}$ & $0.063^{* * *}$ & $0.419^{* * *}$ \\
\hline$\rho_{\text {Child,Parents }} \frac{s d(\text { Child })}{\text { sd(Parents })}$ & $0.201 \frac{0.860}{0.491}$ & $0.268 \frac{0.977}{0.840}$ & $0.214 \frac{0.375}{0.308}$ & $0.318 \frac{0.906}{0.645}$ & $0.081 \frac{1.004}{1.989}$ & $0.256 \frac{0.970}{0.860}$ & $0.075 \frac{0.561}{0.669}$ & $0.280 \frac{0.923}{0.615}$ \\
\hline
\end{tabular}

Note: Table shows coefficients $\left(\beta^{I G E}\right)$ and standard errors from regressions on parental log income on child's log income from Table 1 together with the correlation multiplied with the ratio of the standard errors $\beta^{I G E}=\rho_{\text {Child,Parents }} \frac{\text { sd( (Child })}{\text { sarents })}$ for Denmark and the U.S

From this analysis, we see that IGE estimates are sensitive not only to the income measures used, but also to inequality levels and changes. It is not meaningful to compare IGE estimates, when arbitrary large or small levels of inequality drive the estimates. In order to investigate this issue more deeply, we conduct a further analysis showing the sensitivity of IGE estimates to adjustments for inequality.

We present regressions where we transform the different income distributions for Denmark to the corresponding income distributions for the U.S., holding income ranks fixed. Then we place the U.S. distribution in the Danish distribution. In the upper panel of Table 3 , we present IGE estimates where quantiles of the Danish distributions (for parents (reported in the rows) and children (reported in the columns)) are mapped into the equivalent income measures for the U.S. for children born in 1973-1975 in 2011 with parents in the 1987 March CPS data. Figure $\mathrm{A} 2 \mathrm{a}$ in the Web Appendix illustrates the transformation for wage earnings distributions. 
The child or parent with the $n^{\text {th }}$ total gross income rank in Denmark is assigned the total gross income level associated with the $n^{\text {th }}$ rank of total gross income for the U.S. child or parent distribution. A similar transformation is used for total income excluding public transfers, total net-of-tax income, wage earnings, and wage earnings plus public transfers. Using this method, we illustrate what the Danish IGE would be for the different income measures, if Denmark had the same level of inequality within generations as those found in the U.S.

In the lower panel of Table 3, we do the opposite, which is illustrated in Web Appendix Figure A2 b. In this case, quantiles of the U.S. distributions are mapped into the equivalent income measures in 2010-2012 for Danish for children born in 1973-1975 and their parents using Danish register data. Hence, we illustrate what the U.S. IGE would be for the different income measures, if the U.S. had the same level of inequality within generations as those found in Denmark.

The columns and rows labeled Baseline distribution for both parents and children show the actual IGE coefficients from Table1. The first line in the upper panel shows that if Danes born between 1973 and 1975 had the same income distribution as the corresponding U.S. age cohorts, the Danish IGE estimates for gross income excluding transfers, including transfers, and net-of-tax would increase by 50 to $100 \%$, whereas it would be unchanged for wage earnings. In the next thought experiment, we examine the consequences of giving Danish parents the same income distribution as U.S. parents. Estimated IGEs would decrease. Transforming children's and parents' income distribution reduces IGEs by $30-50 \%$ when we consider the gross income measures, and increase IGEs by roughly $50-100 \%$ when we consider wage earnings and wage earnings plus transfers.

When we perform the equivalent exercise for the U.S., we naturally reach the opposite conclusion. Changing income distribution of children and holding parents' income distributions fixed results in large reductions in the IGE, while changing income distributions for parents 
and holding children's income distributions fixed results in large increases in the IGE. Finally, by transforming both generations' income distributions, the IGE by gross income excluding transfers increases, the IGE transfers decrease, and the IGE for wage earnings is unchanged.

Table 3 shows that IGEs in Denmark and the U.S. are quite different when wage earnings and wage earnings plus transfers are used as measures of income. Estimated IGEs based on these two income measures are robust to the changes in inequality we observe for both countries. For the remaining measures of income, the similarities between the IGEs in Denmark and the U.S. are substantial and depend strongly on trends and levels in inequality.

The analyses presented in this section emphasize that levels of estimated income (im)mobility often is in the eye of the beholder. Not only do estimates vary by income measures, they are also affected by whether changing inequality is linked to mobility. For example with a fixed correlation between children's and parents' income, doubling income inequality from one generation to the next clearly increases differences in income levels and the consumption possibilities between children from high income and low income families. Should the chosen measure of income mobility capture such change? Without specifying a social welfare function and a normative definition of fairness, this question does not have a clear answer. 


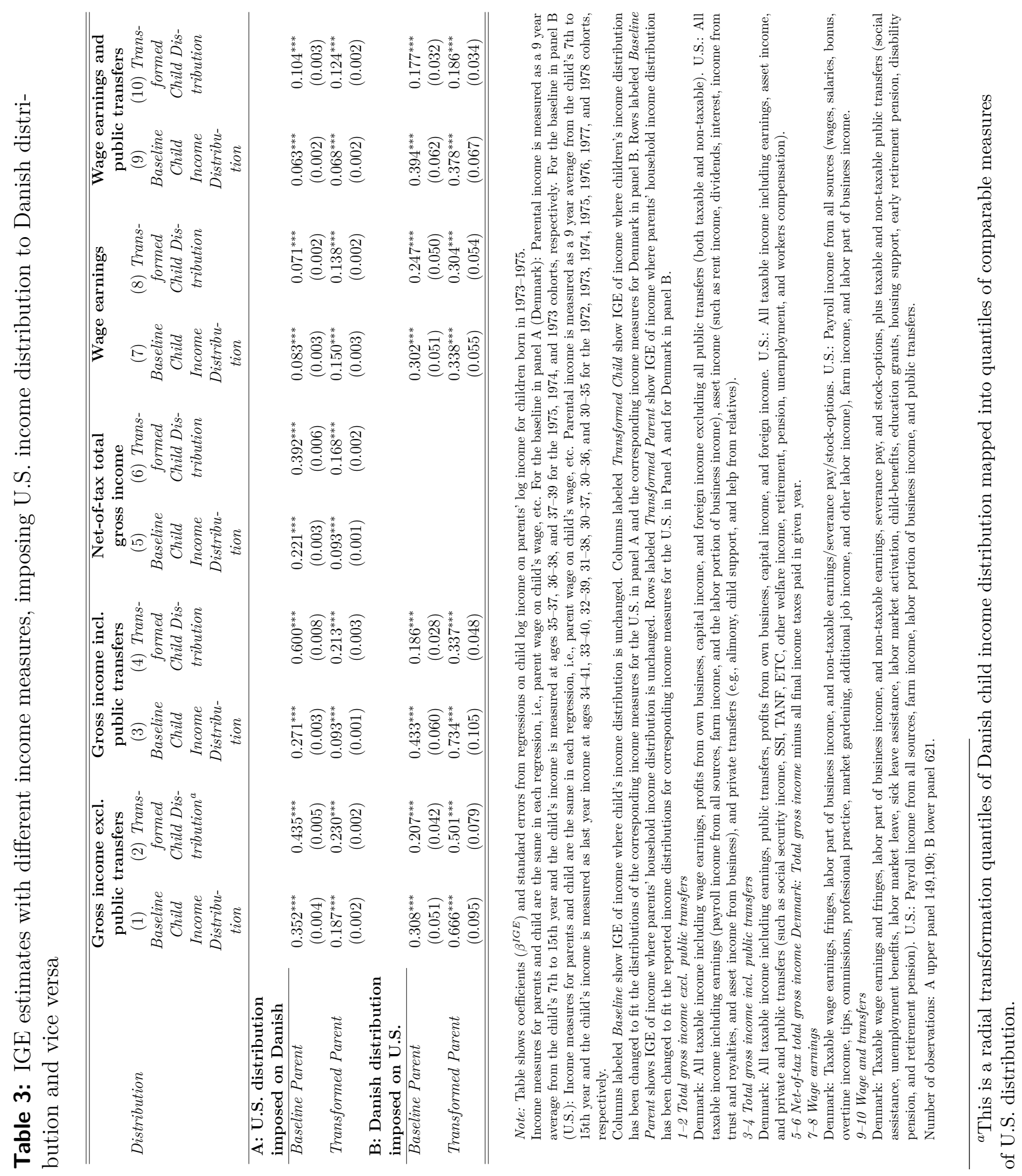




\subsection{Nonlinear Intergenerational Income Elasticities}

It is likely that any benefits from the Scandinavian welfare states accrue to the least advantaged. This is a feature that linear models of the IGE might fail to adequately capture. Thus, it is particularly interesting to analyze nonlinearities in the IGEs. Wage compression and the high level of redistribution via taxes and transfers only add weight to the relevance of considering possible nonlinearities.

Yet, few previous studies consider nonlinearities. Bratsberg et al. 2007 ${ }^{20}$ report that the relationship between the logarithm of child and parent income is convex in Denmark (and in Scandinavia more generally) and concave in the U.S. for measures of wage earnings. They attribute this finding to higher mobility for individuals from low income families in Denmark than in the U.S. We replicate these findings in Figure A3 in the Web Appendix. However, as previously emphasized, results differ according to which income measure is used. In Denmark for example, wage earnings of children and parents display a convex relationship, while for total gross income excluding public transfers the relationship is linear, or perhaps even concave.

To account for nonlinearities, we estimate the Nonlinear Intergenerational Income Elasticity (NL-IGE) $\beta^{\mathrm{IGE}}\left[\ln \left(Y_{0}^{P}\right)\right]$, where $Y_{0}^{P}$ is the income of the parent at $Y_{0}$ and $Y^{C}$ is income of the child, using Local Linear Regressions ${ }^{21}$

$$
\min _{\alpha\left[\ln \left(Y_{0}^{P}\right)\right], \beta\left[\ln \left(Y_{0}^{P}\right)\right]} \sum_{i=1}^{N} K_{h_{\lambda}}\left(Y_{0}^{P}, Y_{i}^{P}\right) \cdot\left\{\ln \left(Y_{i}^{C}\right)-\alpha\left[\ln \left(Y_{0}^{P}\right)\right]-\beta^{I G E}\left[\ln \left(Y_{0}^{P}\right)\right] \ln \left(Y_{i}^{P}\right)\right\}^{2} .
$$

It is feasible to estimate the NL-IGEs using absolute income, thereby obviating the problem

\footnotetext{
${ }^{20}$ Björklund et al. (2012), Chevalier et al. (2013), and Davies et al. (2005) also study nonlinearities.

${ }^{21}$ Estimates closely resemble the slopes found in the plots of log of child and parental income in Figures A3 and A4 in the Web Appendix.
} 
that $\ln (0)$ does not exist. ${ }^{22}$ However, the estimation of NL-IGE using absolute income involves a tradeoff in terms of precision for high income levels due to the right tail of the income distribution. Doing so reduces the precision of estimates substantially. In order to be able to compare estimates from $\$ 10,000-125,000$ and not just from $\$ 30,000-60,000$ of parental incomes, we therefore report estimates using log income here. The equivalent point estimates using absolute income are very similar to the results shown in the main text and are reported in Web Appendix Figures A5 and A6.

Figures 1 and 2 show plots of NL-IGE estimates of log income, weighted with absolute income, without imputation for zero income for Denmark and the U.S. The vertical lines in the figures mark the 5th and 95th percentiles in the income distributions in the Danish data and the 5th and 95th percentiles for the U.S. data. These estimates only allow us to infer local conclusions about mobility. A zero IGE estimate at a low level of income does not imply that going from rags to riches is likely. It only shows that a marginal movement up (or down) in income levels relative to parental income is just as likely as a status quo. The figures present estimates for the income ranges where the data allows us to make meaningful estimates (because there is very limited support for high incomes in the PSID).

Figure 1 shows NL-IGE estimates for gross income excluding public transfers and gross income including public transfers for Denmark and the U.S. (Figures $1 \mathrm{a}$ and $1 \mathrm{~b}$ ). The elasticity goes from levels around 0.25 to almost 0.4 when parental income increases from $\$ 0$ to $\$ 100,000$. Thereafter, the estimates slowly decline and reach a level of around 0.1-0.2 at the 99th percentile of parental income. The corresponding results for the U.S. (in Figures 1c and 1p) show that elasticities at low income levels closely correspond to those in Denmark, although they are

\footnotetext{
${ }^{22} K_{h_{\lambda}}\left(Y_{0}^{P}, Y_{i}^{P}\right)$ is an Epanechikov kernel. One should note that it is important to distinguish between a kernel with absolute income $K_{h_{\lambda}}\left(Y_{0}^{P}, Y_{i}^{P}\right)$ which we use here, and a kernel with log income $K_{h_{\lambda}}\left(\ln \left(Y_{0}^{P}\right)\right),\left(\ln \left(Y_{i}^{P}\right)\right)$. The former assigns symmetric weight around $Y_{0}^{P}$ while the latter weighs observations above $Y_{0}^{P}$ more because of the logarithmic transformation. Finally, the imputation of zero incomes inflates estimates of NL-IGEs at the low to medium parental income range (the parental income ranges where zero incomes for children are most prevalent).
} 
imprecisely estimated. In the U.S., elasticities increase monotonically with parental income. At the 95th percentiles of parental gross income excluding and including public transfers, U.S. intergenerational income elasticities are well above 0.5 .

Figure 2 graphs NL-IGE estimates for wage earnings and wage earnings plus public transfers for Denmark (a and b) and the U.S. (d and e), and net-of-tax total gross (disposable) income for Denmark (c). Figures $2 \mathrm{a}$ and $2 \mathrm{p}$ show functional forms similar to those from Figures $1 \mathrm{a}$ and 1 $\mathrm{b}$. Elasticities at low levels of income are approximately 0.1, or even lower, and increase monotonically until parental income reaches $\$ 110,000$. After this point, the elasticities decrease. For the U.S., the figures also show a monotonic upward slope but with levels well above the Danish estimates at all points. Finally, elasticities for net-of-tax income in Denmark are initially flat at roughly 0.25 but go towards zero as parental income increases beyond the 99th percentile. 
Figure 1: Local Intergenerational Income-Elasticity in Denmark and the U.S.

(a) Denmark

(a) Total gross income excl. public transfers

(b) Total gross income incl. public transfers
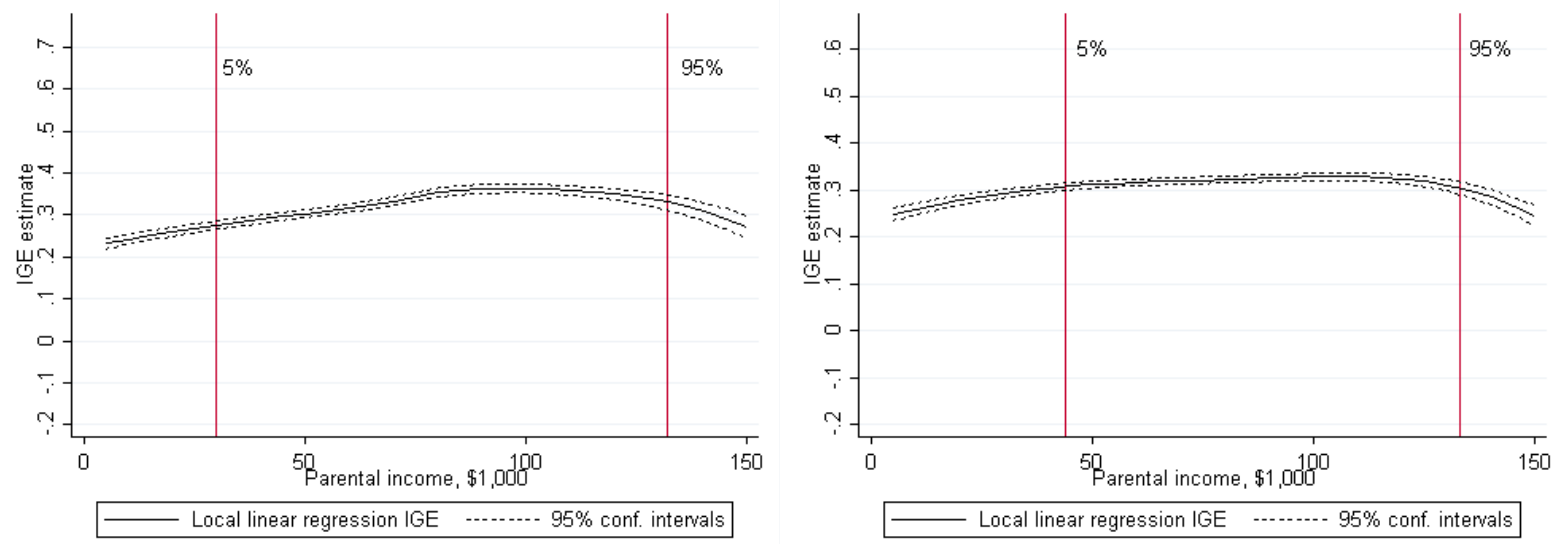

(c) Total gross income excl. public transfers

U.S.

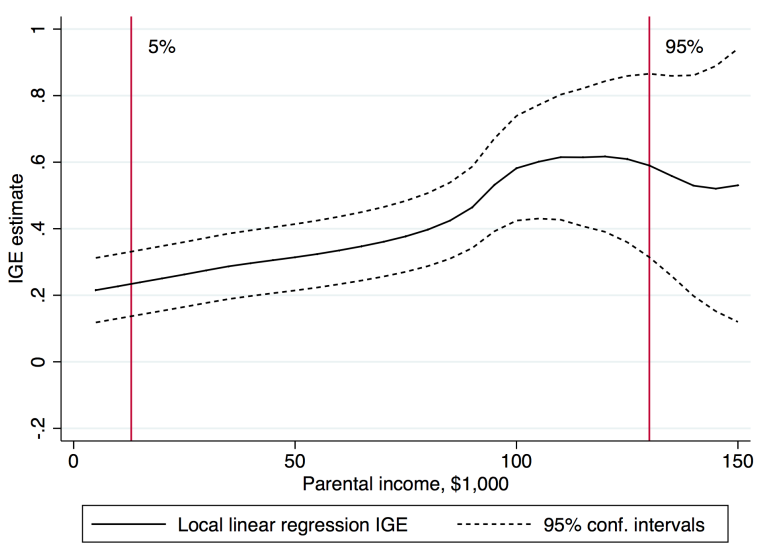

(d) Total gross income incl. public transfers

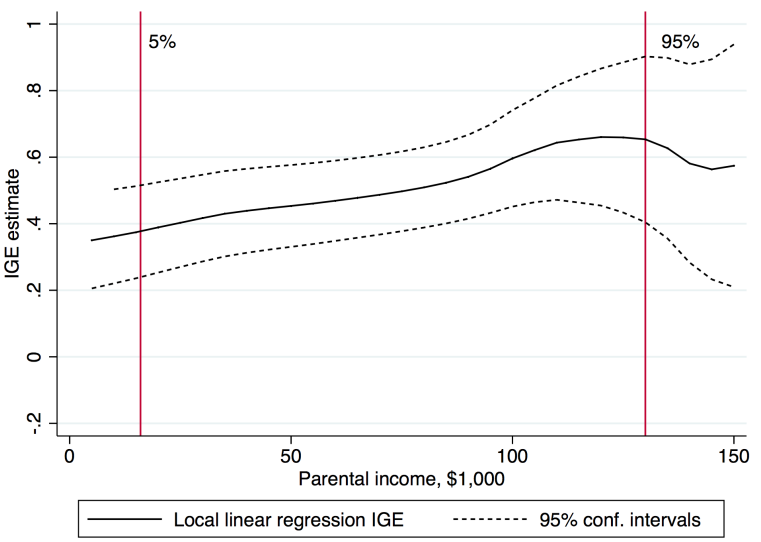

Note: Figures show estimated Intergenerational Income-Elasticities of wage income plus public transfers for Denmark (a, b) and the U.S. (c, d). Figures a and b have been constructed using full population register data from Denmark, and Figures c and d and have been constructed using PSID data. The figures show local linear regression slopes of $\log$ of children's income on log of parental income. LLRs are weighted using kernels of absolute income. Standard errors for Figures a and b have been constructed from 50 bootstraps and standard errors for Figures c and $\mathrm{d}$ have been constructed from 1,000 bootstraps.

The vertical lines indicate the 5 th and 95 th percentiles in the respective income distributions. 


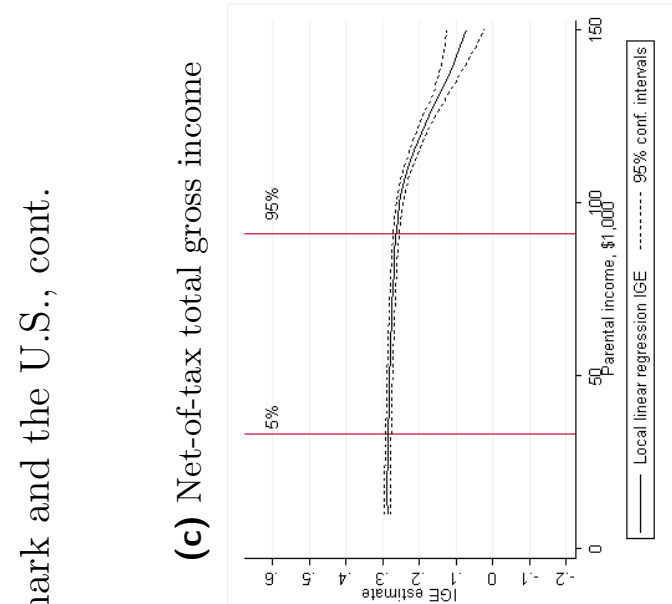

ปี

.$\exists$

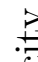

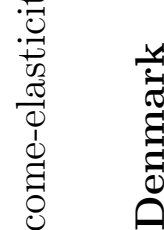

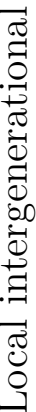

$\ddot{N}$

这
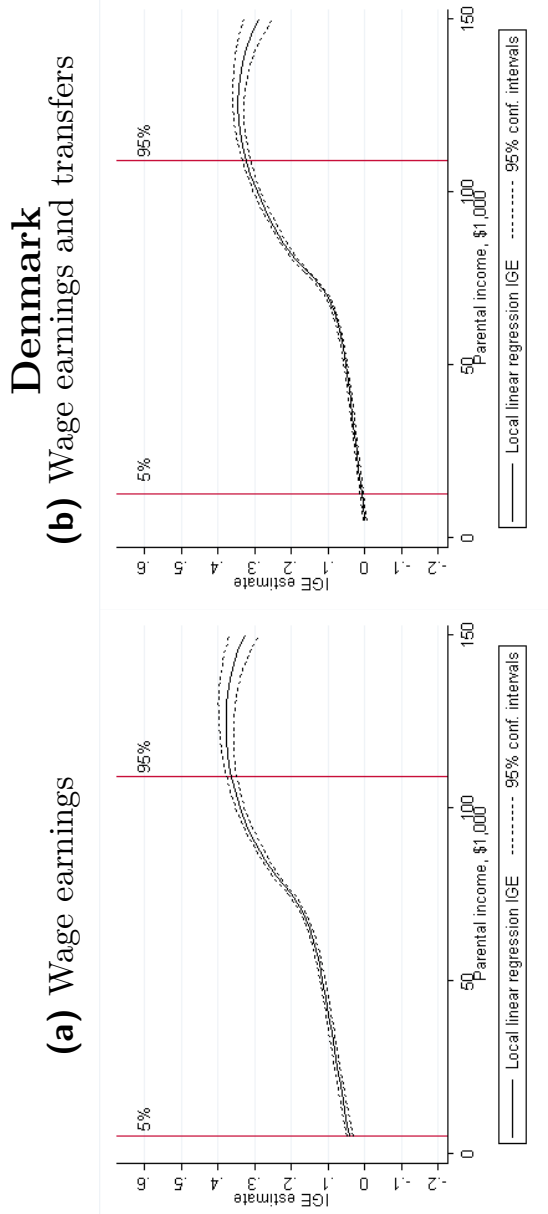

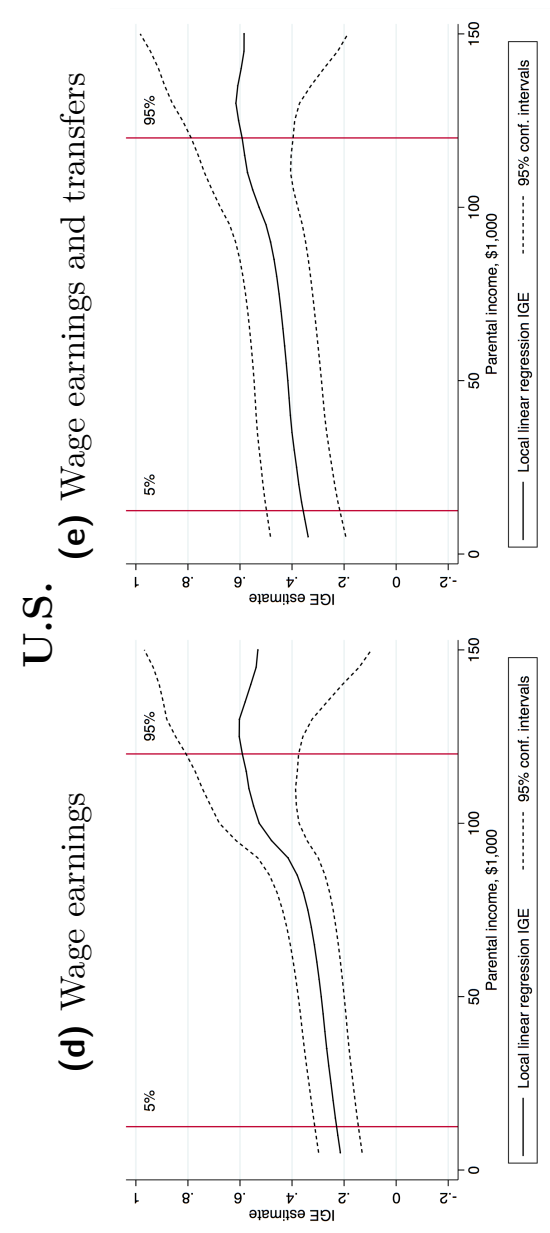

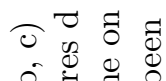

s. 000

忚 $\Xi$

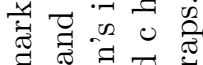

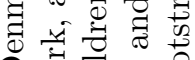

ด สี

矛藏 के

क 0 कo 8

무의

ซี

$\forall$ क

. त्वृ क्ष

苛

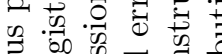

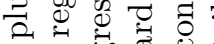

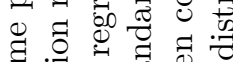

ర용

$\exists \approx .00$

ه

今

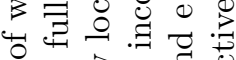

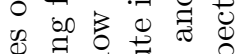

.

它

社

d

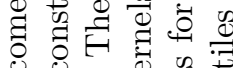

过

卷

궁

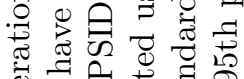

ㄱㄷㄴ

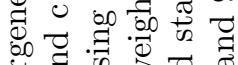

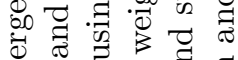

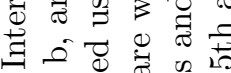

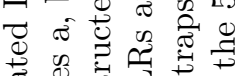

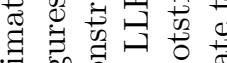

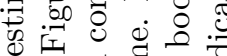

$\dot{0}$.

क

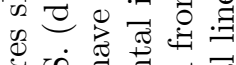

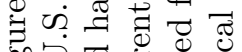

垊

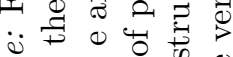

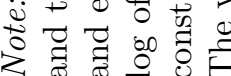


In order to get a more precise view of the cross-country differences in NL-IGEs, Figure 3 plots the differences between the U.S. and the Danish elasticities across levels of parental income. From Figure 3 a we see that income mobility in gross income excluding public transfers is roughly similar for family incomes up to $\$ 100,000$. From this point onward, a gap emerges which - albeit imprecisely estimated - continues to increase. Income mobility by gross income excluding transfers is much lower in the U.S. than in Denmark for top quartile family incomes, but not for families with low income. When transfers are added to income, as shown in Figure 3b, the elasticities in the U.S. are persistently above the Danish elasticities with a widening gap at high incomes. When we only consider wage earnings in Figure 3c, the Danish IGE is around 0.2 lower than the U.S. IGE across all parental income levels. This result also dovetails nicely with our argument about the importance of wage compression in Denmark as opposed to the increasing return to education in the U.S. being key mechanisms behind the observed income mobility differences. Finally, Figure $3 \mathrm{~d}$ shows that for wage earnings plus transfers, intergenerational income elasticities in Denmark are consistently below U.S. levels. Here, the Danish IGE is around 0.35 lower than the U.S. IGE at low income levels and 0.25 lower at high income levels. Hence, the largest difference between income mobility in Denmark and the U.S. is now for the lowest family incomes. 
Figure 3: U.S.-Denmark difference in local Intergenerational Income-Elasticity

(a) Total gross income excl. public transfers

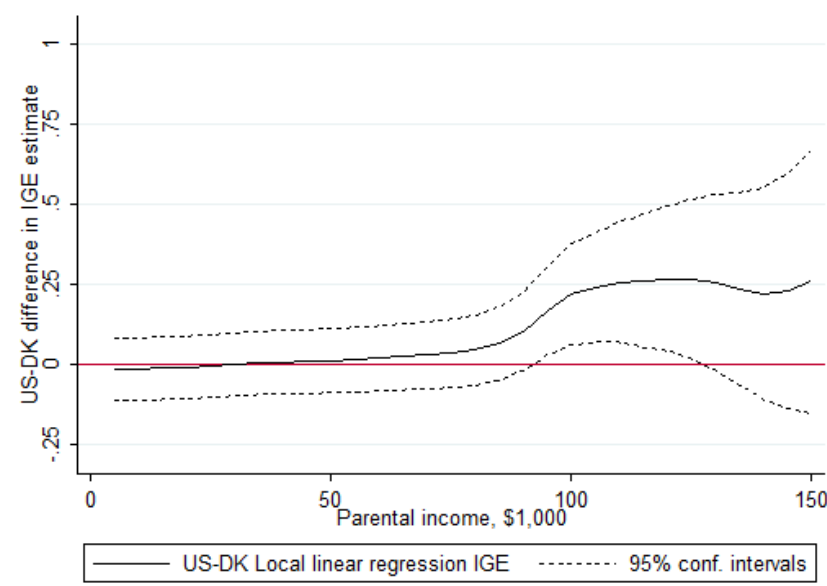

(c) Wage earnings

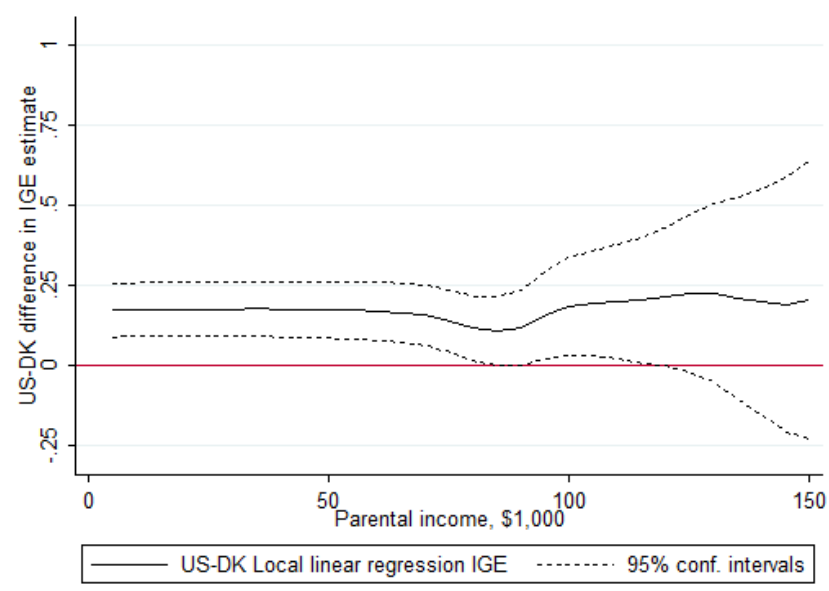

(b) Total gross income incl. public transfers

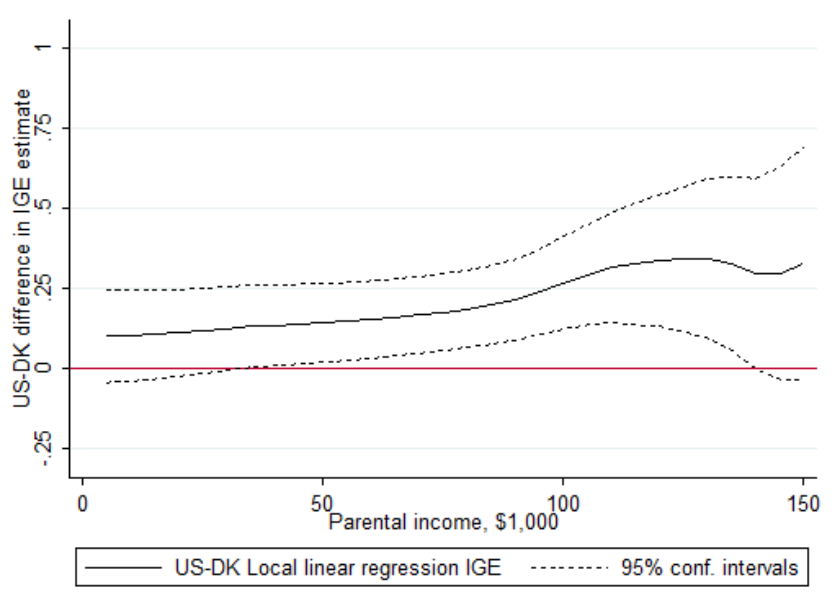

(d) Wage earnings and transfers

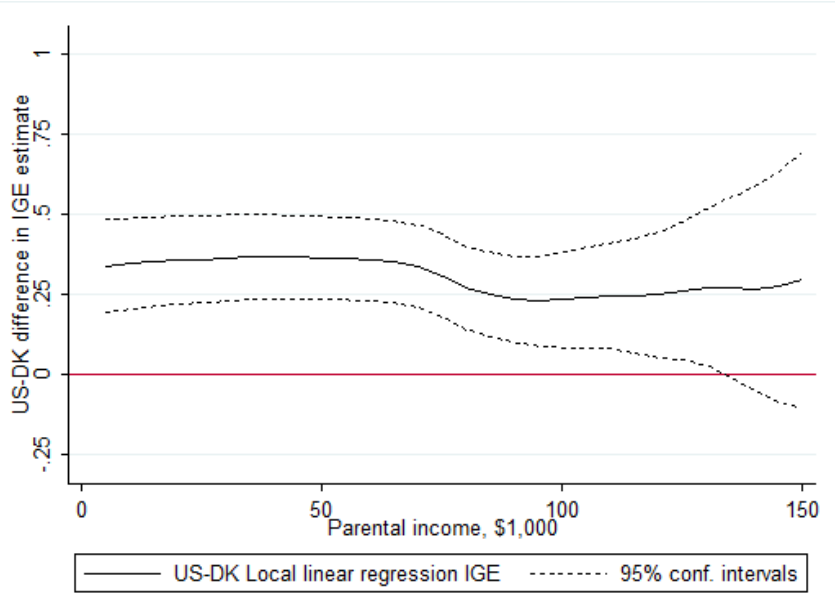

Note: Figures show U.S.-Denmark difference in local Intergenerational Income-Elasticities from Figures 1 and 2 The figures show the U.S. IGE estimate minus the Danish estimate, such that a positive value indicates a larger IGE estimate for the U.S. than for Denmark and a negative value indicates the opposite. 


\section{Educational Mobility by Family Background}

In the previous section, we studied intergenerational income mobility across two countries and show that wage compression and tax/transfer policies are major determinants of cross-country differences in mobility. Although the reward for education may be lower in Denmark, its generous support of education, support of child care, and early education initiatives promotes skill formation as measured by test scores among the disadvantaged.

Many point to the more generous educational and child care policies in place in Denmark as a source of its greater social mobility (see, e.g., Sanders, 2013). We examine this claim and show that average educational mobility is remarkably similar across the two countries. We start by demonstrating the near-universal participation in such programs in Denmark coupled with a lack of educational and income differences compared to the U.S. ${ }^{23}$

Figures $4 \mathrm{a}$ and $4 \mathrm{~b}$ show the fraction of children enrolled in preschool programs at the age of 4 in the U.S. and Denmark from 1995 to $2005{ }^{24}$ The figures show overall rates together with

\footnotetext{
${ }^{23}$ Throughout this section we use a variety of data sources. We discuss these briefly in the main text. Web Appendix Section $\mathrm{F}$ describes them in detail.

${ }^{24}$ See Tables A13 and A14 in the Web Appendix for an overview of the expenditures on education systems in the U.S., Denmark, and the rest of Scandinavia. They demonstrate the greater generosity of the Danish system measured in a variety of ways. Expenditures on preschools are especially generous. Currie (2001) and Simonsen (2010) give detailed descriptions of expenditures and pricing schemes in early education in the U.S. and Denmark, respectively.

${ }^{25}$ The Scandinavian daycare and preschool system is rooted in a social pedagogy tradition as opposed to many other European countries and the U.S., which focus more on an educational approach (Organisation for Economic Co-operation and Development, 2001, 2006). 'The English-speaking world have adopted a 'readiness for school' approach, which although defined broadly focuses in practice on cognitive development in the early years, and the acquisition of a range of knowledge, skills, and dispositions. A disadvantage inherent in this approach is the use of programmes and approaches that are poorly suited to the psychology and natural learning strategies of young children. In countries inheriting a social pedagogy tradition (Nordic and Central European countries), the kindergarten years are seen as a broad preparation for life and the foundation stage of lifelong learning.' (Organisation for Economic Co-operation and Development, 2006, pp. 2). The Nordic approach is summarized as 'The core of the curriculum is the dialogue between adult and child and creative activities, discussions and reflections. The curriculum sets goals for early education, but is flexible so that it can be adapted to local and individual needs.' (Taguma et al., 2013. Table 2.1) In recent years, however, early childhood care in Denmark has increased its focus on education as well (see Jensen et al., 2010, for a discussion).
} 
the rates for children for whom both parents have fewer than 12 years of schooling (less than high school) and children for whom both parents have at least 15 years of schooling (college or more). The figures show that average preschool enrollment rates at age 5 were, on average, similar in the two countries in 1995. Since then, rates of participation have stagnated in the U.S. and increased to a level close to full uptake in Denmark. Importantly, the figures also show large gaps in enrollment rates by parental education in the U.S., whereas there are no differences in Denmark.

Figures 4 and 4 show rates of daycare/preschool use at ages 2, 3, and 4 by parental wage income rank in 2005 in the two countries. Enrollment rates are lower in the U.S., trends in participation are flatter, and family income gradients for participation in the programs are steeper.

A few studies present causal evidence linking access to universal public child care to improvements in skills in a Scandinavian context. Havnes and Mogstad (2011b) study a large expansion of child care in Norway on long-run outcomes. They find that daycare enrollment improves educational attainment and earnings, especially for children from low-resource families 26 Datta Gupta and Simonsen (2010, 2012) investigate the effects of home care, non-parental/related family care ${ }^{27}$ and public daycare in Denmark on socio-emotional skills. Datta Gupta and Simonsen (2010) find that public daycare relative to family care increases socio-emotional skills at age 7, while Datta Gupta and Simonsen (2012) suggest that the effects may fade at later ages.

An active literature investigates the effectiveness of early childhood interventions in the U.S ${ }^{28}$ The evidence from many U.S. programs may not be relevant to the current discussion,

\footnotetext{
${ }^{26}$ Havnes and Mogstad (2011a|b) show that most of the uptake in publicly provided child care comes from children who were in informal care arrangements. We return to this point in our conclusion.

${ }^{27}$ In a child-minder's home.

${ }^{28}$ Currie and Thomas $(2000)$ and Elango et al. (2016) are examples.
} 
as the programs are often very intensive and target specific groups of children. Cascio (2009) reports that large-scale, publicly funded child care programs in the U.S. are less effective than their Scandinavian counterparts. She suggests that low-intensity programs crowd out other programs - for example, Head Start-and divert funding from other public skill formation initiatives.

While the cited studies only investigate policy changes within a given country, they support the claim that increased early childhood investments through universal public child care, improve the skills of the least advantaged children and thus, intergenerational skill mobility. The evidence for their effectiveness is supported by Figure 5, which shows distributions of PISA math and reading scores in Denmark and the U.S. in 2003 ${ }^{29}$ The figure shows stark differences in the lower tails of PISA test scores. The lowest quartile in the U.S. performs much worse than the lowest quartile in Denmark.

Yet, despite the greater provision of early childhood education to low-resource families in Denmark, the lack of any pecuniary costs of education in Denmark and the compressed skill distributions, the association between educational attainment levels from one generation to the next are remarkably similar in Denmark and the U.S. Figure6 6 shows the fraction of 20-34 year olds in (or with) a tertiary education, by parental educational attainment in Denmark, the U.S., and Norway. The figure shows that only $6-8 \%$ of individuals age $20-34$ who are enrolled in or have completed a tertiary education come from homes where both parents have not graduated an upper secondary education. Generally, there are few differences in these percentages across the three countries. Figure A13 and Section B.2 (Figure A30) in the Web Appendix corroborate this evidence. Web Appendix Figure A13 shows that educational mobility in Denmark is not higher than in the U.S. if we instead consider regression-based coefficients relating children's and parents' educational attainment as reported in Hertz et al.

\footnotetext{
${ }^{29}$ Web Appendix Figures A7 and A8 provide similar results for adults using PIACC and IALS data.
} 
(2008). Educational transitions across generations are very similar in the two countries for more recent cohorts, as we show in Web Appendix Figure A30.

Figure 4: Daycare and preschool use

(a) Trend in preschool participation, age 4 , U.S.

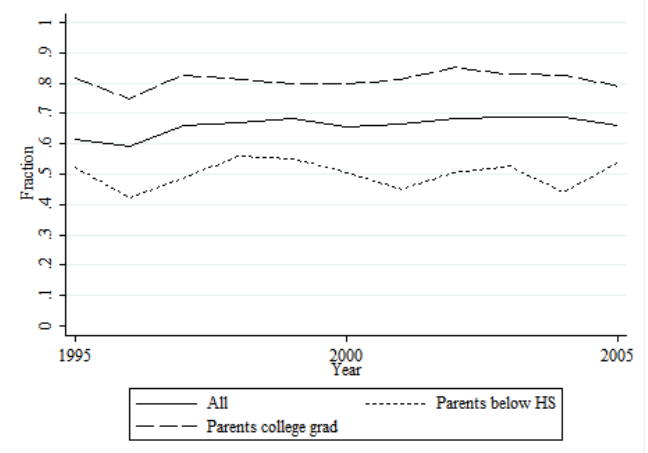

(c) Daycare/preschool by parental income U.S., 2005

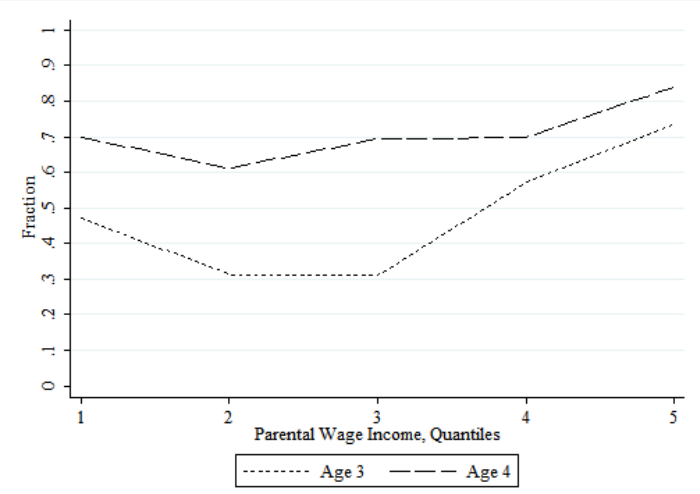

(b) Trend in preschool participation, age 4, Denmark

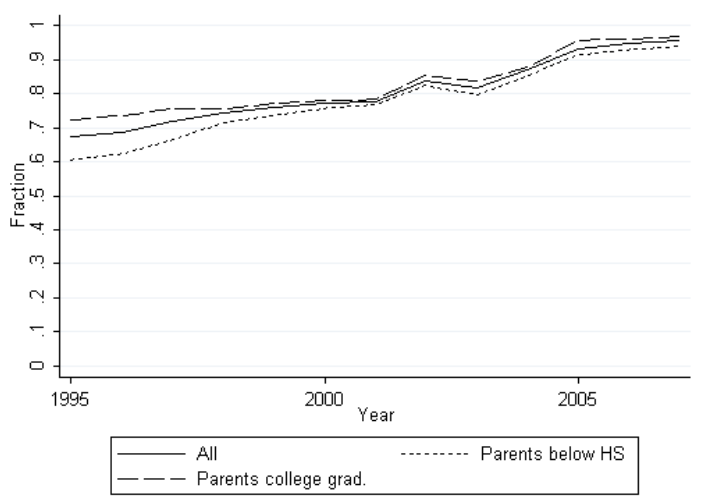

(d) Daycare/preschool by parental income Denmark, 2005

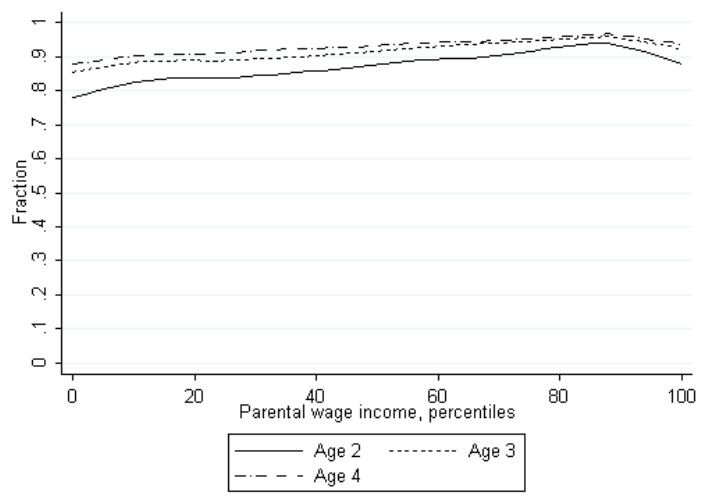

Note: Figures a and b show fraction enrolled in preschool at age 4 from 1995-2007 for all children and by parents' education. Figures c and d show fraction in daycare/preschool by parental wage income rank within child cohort in 2005. U.S. figures constructed from October CPS data, Danish figures constructed from administrative register data. 
Figure 5: Percentage of students at each proficiency level, PISA 2003

(a) Mathematics Scale

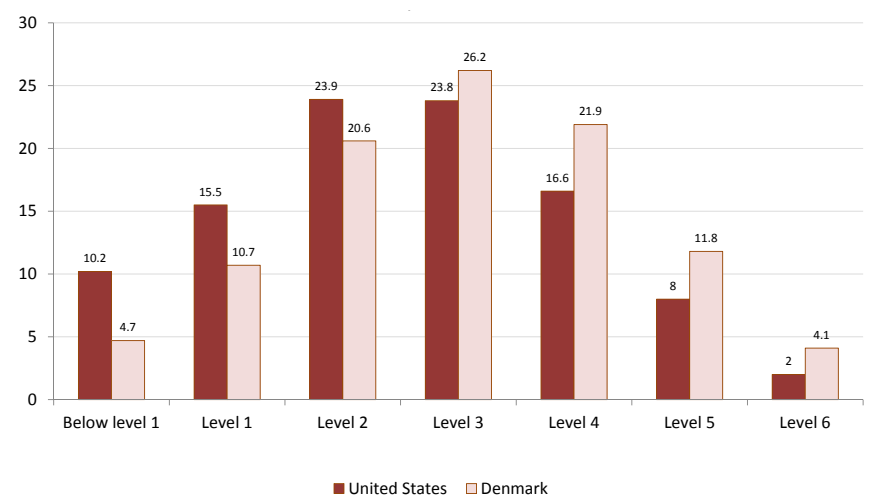

(b) Reading Scale

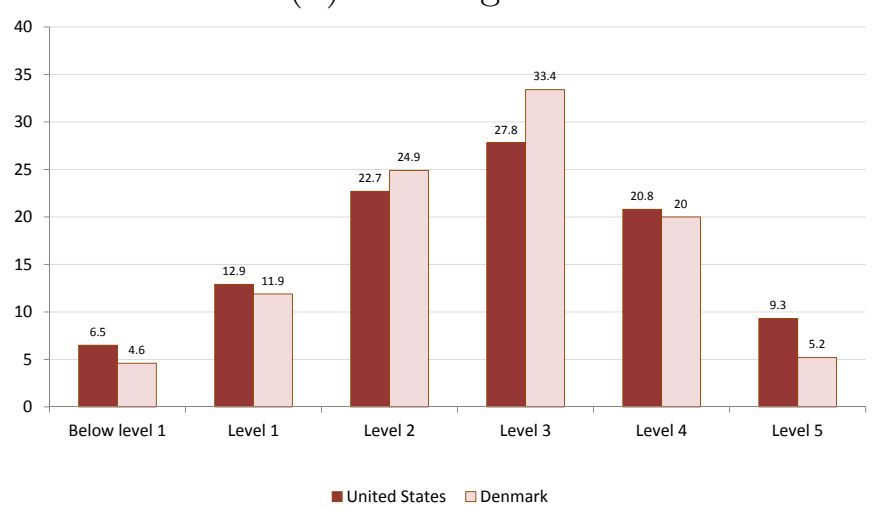

Source: Organisation for Economic Co-operation and Development (2004).

In the rest of this section, we elucidate these findings and investigate the reasons why seemingly similar levels of educational mobility arise. First, we briefly describe the data used in our analyses. We then examine educational attainment by parental resources and which factors help explain the relationship between children's education and parents' resources. We also consider explanations that link the findings from our different analyses. 
Figure 6: Proportion of 20-34 year olds in tertiary education, by parents' educational attainment, Denmark, Norway, the U.S.

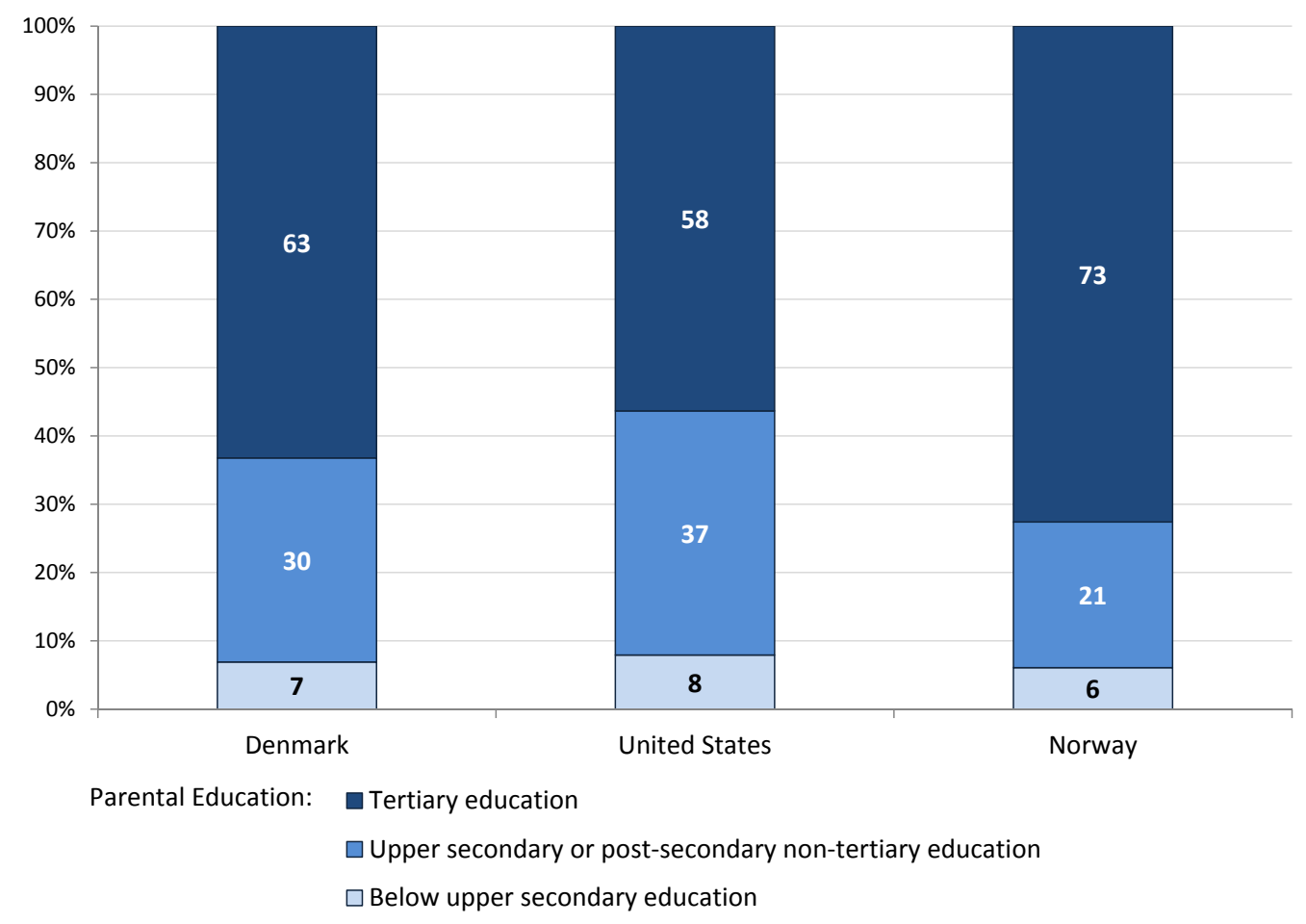

Note: Figure shows proportion of 20-34 year olds in tertiary education, by parents' educational attainment (below upper-secondary, upper secondary or post-secondary (non-tertiary), and tertiary education) in 2012, for Denmark, Norway, and the U.S.

Source: Organisation for Economic Co-operation and Development 2014, Chart A4.1). 


\subsection{Data}

U.S. data: CNLSY. We restrict the sample to cohorts born in 1991 or earlier ${ }^{30}$ In addition to information on own characteristics, we include information on mother's characteristics from the original NLSY data. We restrict the sample to individuals for whom we observe at least one test score for both cognitive and non-cognitive skills (see below), along with parental income. This leaves us with a sample of 3,268 individuals. We lose $15 \%$ due to missing observations and $28 \%$ of the remaining sample are born in 1987 or later. See Web Appendix Table A19 for sources of loss of sample information.

Danish data: 1987 Cohort. We use the entire cohort of children born in Denmark in 1987. Using a unique individual identifier, we link information on demographic characteristics to schooling outcomes and exam grades in 9 th grade 31 The data also include a unique parental identifier, which allows us to link the information on the children to parental income and wealth, demographic characteristics, and mother's educational attainment. We restrict the sample to children whose parents have non-negative household wage income in 2002. This results in a sample of 39,539 children. 32

Comparability of samples. There are two fundamental differences between the Danish and U.S. samples. First, while the latter is survey data, the former comes from a full population register based on information reported from relevant institutions and authorities. Second, Danish data are centered around child's birth year, while consequently, cohorts vary in their characteristics in the two countries. The CNLSY data is centered around parents' birth year, as it is based on children born from five cohorts of parents. In the CNLSY, we record information

\footnotetext{
${ }^{30}$ Roughly $10 \%$ are born before 1980 . Modal years are 1981-1991 where $6.5-8.5 \%$ of sample are born each year.

${ }^{31}$ Primary school grades are not binding for the child's further educational trajectory for this cohort.

${ }^{32}$ See Web Appendix Table A19 for sources of loss of sample information.
} 
on multiple cohorts of children (before and after 1987) and only five cohorts of mothers. For the Danish data, we consider only one cohort of children born in 1987 and numerous cohorts of parents. We do not censor the data to align parents' and children's cohorts between the two countries, as this would induce heavy selection in terms of mother's age at childbirth. As female fertility patterns are different between the U.S. and Denmark, such selection imposes arbitrary differences between the two countries and could consequently invalidate the analysis ${ }^{33}$

Measuring income and wealth. In the CNLSY data, we measure parental income using the sum of the mother's and the spouse's self-reported wage earnings. In the Danish data, we measure parental income as the sum of the mother's and father's wage earnings ${ }^{34}$ For both countries, we measure income as average income between the child's 3rd and 15th year. The two income concepts are similar in content.

For the U.S., we measure assets as reported net assets in the CNLSY 35 For Denmark, assets are measured as net assets (excluding pension savings) from income and wealth data reported to tax authorities 36 In both countries, we measure assets at age 15 of the child. While the data again differ in terms of source, net assets are highly dependent on housing wealth 37 Thus, intra-country differences in wealth may capture both differences in market luck in the housing sector, family endowments, and lifetime income. ${ }^{38}$

\footnotetext{
${ }^{33}$ Table A15 presents regression coefficients of parental permanent wage income and wealth on children's high school completion and college attendance where we sample cohorts in the Danish register data with the same distribution as observed in the CNLSY data, and where we sample number of observations in each cohort as observed in the CNLSY data. The results do not differ significantly or qualitatively from our main results, which we will present in Table 4

${ }^{34}$ Results are robust to using gross income including UI and welfare transfers.

${ }^{35}$ They include value of major owned durables (e.g., housing), as well as debts.

${ }^{36}$ Includes valuations of major owned durables.

${ }^{37}$ See Browning et al. (2013) for a discussion of Danish data.

${ }^{38}$ Home equity comprises a larger share of households' net wealth in Denmark than in the U.S. In 2010, home equity was estimated as approximately $24 \%$ of households' net wealth in the U.S. (Gottschalck et al., 2013). In Denmark in 2014, this was 37.5\% (Statistics Denmark, 2016). Reported shares for both countries include pension savings in total net wealth.
} 
Measuring education. In the U.S. data, high school completion is defined using questions on whether or not the child has a high school diploma/GED ${ }^{39}$ We define college attendance as a report of either full- or part-time enrollment in college. In the Danish data we define high school completion as having completed an education that requires at least 12 years of schooling, which includes both academic and vocational high school graduates, and college as having been enrolled in an education that requires at least 15 years of schooling 40

Cross-country institutional differences are a potential confounder. While we have chosen our definitions of high school completion and college attendance to maintain comparability, we do not (and cannot) control for all cross-country institutional differences. Two potentially

\footnotetext{
${ }^{39}$ Cameron and Heckman (1993) and Heckman et al. (2014) show that these two concepts are not equivalent. However, omitting the GED from the definition of high school completion would likely reduce the similarities of Denmark and the U.S., as the Danish measure of high school completion also includes a version of the GED (HF). The HF is a substitute high school degree designed for those who dropped out of high school or earlier educational levels before they completed this. While GPAs from the HF provide access to further education and university as regular academic high school (Gymnasium) does, HF graduates have lower average levels of completed schooling and lower adult income (likely because HF completion instead of Gymnasium completion, for a given GPA, proxies fewer skills on other dimensions (Heckman and Rubinstein, 2001)). Students often take the HF at older ages than normal high school students. Some are high school dropouts while others haven't enrolled in high school, but dropped out of education after the compulsory years and have spent 5-10 years out of the educational system.

${ }^{40}$ The Danish educational system is rooted in a Northern European tradition and is not directly comparable to the U.S. system, while secondary and tertiary educations in Denmark are highly comparable to those in countries as Germany and Norway. Our definitions of 'high school' and 'college' bring the U.S. and Danish system closer, both qualitatively and in population means. However, this simplification of the Danish educational ladder reduces comparability to other Scandinavian schooling systems, unless similar simplifications are made there as well. Figure A52 in the data section of the Web Appendix illustrates how the two schooling outcomes are affected by our definitions and age restrictions in Denmark.
} 
problematic issues are social promotion 4 and the minimum school leaving age ${ }^{42}$ which may distort the levels of human capital associated with equal levels of schooling in Denmark and the U.S.

Measuring skills. For the U.S., we use the Peabody Individual Achievement Test (PIAT) scores to measure cognitive skills. The CNLSY features three sets of PIAT scores: reading recognition, reading comprehension, and math. For non-cognitive skills we use the antisocial, headstrong, hyperactivity subscales from the Behavior Problem Index (BPI). The measures of cognitive skills and non-cognitive skill are in accordance with those of, e.g., Cunha and Heckman (2008) and Heckman et al. (2006).

For Denmark, we measure skills using grades from the 9th grade. Cognitive skills measured are residualized by non-cognitive measures. Exam grades (even cognitive ones) are highly dependent on non-cognitive skills (the final year of compulsory schooling, i.e., before they begin high school). We measure cognitive skills using final math exam grades (written), math midterm grades (written), final physics exam grades, and non-cognitive skills using orderliness/organization/neatness grades from the Danish written exam, Danish written midterm,

\footnotetext{
${ }^{41}$ Social promotion reduces the academic material needed to pass this level. Social promotion may, in a more complex form, result in reducing the academic levels needed to complete a given education, and thus, inflate graduation rates, invalidating cross-country comparisons of the educational levels in question. The phenomenon exists in both countries, evidenced by the substantial attention it has received in the public debate (for Denmark, see Berligske Tidende, 2015, Politiken, 2014, and Produktivitetskommissionen (Productivity Commission), 2014 for examples of a discussion from the public debate. For the U.S., see McCombs et al., 2009, President Clinton, 1998, and United States Department of Education, 1999). There are, however, no data available that allows us to test for differences and/or similarities between social promotion in Denmark and the U.S.

${ }^{42}$ In the U.S., the law dictates that children should attend school until they turn 16-18 (depending upon state). For most states this includes the first year of high school. In Denmark, there is no minimum school-leaving age, but instead a minimum number of years of schooling. Children are not allowed to leave school before they have completed ninth grade. As a consequence, most U.S. children have to begin high school even though they are not forced to complete it. This may induce some to graduate high school who would not have done so in the Danish setting, and thus increase (perceived) educational mobility in the U.S.
} 
and math written exam 43 As test scores and grades are highly associated with non-cognitive skills (Borghans et al. 2011a b), we use residuals from the cognitive measures regressed on the non-cognitive measures in the measurement system to estimate cognitive skills.

\subsection{Unadjusted Education by Parental Resources}

Figures A14 to A14 $\mathrm{d}$ in the Web Appendix show children's educational attainment measured by completion of high school or equivalent (Figures A14 $\mathrm{a}-\mathrm{b}$ ) and enrollment into college or equivalent (Figures A14c-d) by the log of parental wage income and wealth in the U.S. and Denmark 44

Figures A14 and A14p show that, in both countries, rates of high school completion increase in parental income and wealth. In the U.S. data, the relationship has its greatest curvature at low levels of income and wealth, while a gradient is evident across the entire range of parental wealth and income in the Danish data. In both countries, $90 \%$ of children at the top of the income and wealth distribution complete high school, whereas for low levels of income and wealth, approximately $65-70 \%$ complete high school in the two countries. Broadening the income and wealth ranges to all levels of support beyond the ranges where we have an overlap between the two countries, Figure A15 in the Web Appendix shows that individuals whose parents are in the lower end of the distributions are more likely to complete high school in the

\footnotetext{
${ }^{43}$ Our measures of non-cognitive skills in the two countries are clearly not equivalent. The Danish measure of non-cognitive skills are more related to an orderliness/effort measure while the U.S. measure is related to behavioral problems. Another concern when using grades is that our measures of non-cognitive skills are closer related to academic achievement than to socio-emotional skills. We do not consider this an issue in the present case. When we estimate factor loadings and perform variance decompositions from the two factors on outcomes DUI and psychiatric admissions, these outcomes are significantly more associated with non-cognitive (socio-emotional) skills than cognitive skills. The factor for non-cognitive skills explains around three to five times as much of the variance in DUI and mental disorders compared to the factor for cognitive skills.

${ }^{44}$ Web Appendix Figures A16 A16 d show the corresponding results for quantiles of parental income and wealth. The overall pattern and conclusions are unchanged, although gradients do change as a result of the distributional differences between income/wealth in Denmark and the U.S.
} 
U.S. than in Denmark. For parents with low levels of income and wealth, $60 \%$ and $45 \%$ of children in the U.S. and Denmark, respectively, complete high school.

Figures A14: and A14d show that college attendance rates also increase with parental wealth and income. The gradient, with respect to wealth, is larger in the U.S. than in Denmark at the bottom of the wealth distribution. Parental income is only strongly associated with increasing rates of college attendance for families with above-median wealth in the U.S. In contrast, in Denmark, the income gradient is largest for families with below-median wealth. ${ }^{45}$

Finally, Figures A19a and A19b in the Web Appendix show level differences of the surfaces displayed in the previous figures for the areas of income and wealth where we have common support in the Danish and U.S. data. The figures show that levels of high school completion are higher in the U.S. than in Denmark for children from low-income/low-wealth families, while this group's college attendance rates are substantially higher in Denmark than in the U.S.

The figures described above illustrate that levels of social mobility in Denmark do not always exceed social mobility in the U.S. One result in Figure A14 may suggest that mobility is higher in Denmark while another suggests the opposite. We next investigate which mediating factors explain mobility (or lack thereof) in Denmark and the U.S., and whether the role of these factors differ.

\footnotetext{
${ }^{45}$ Figures $\mathrm{A} 17$ and $\mathrm{A} 18$ in the Web Appendix show rates of high school completion and college attendance by wage income and wage income plus public benefits in levels and ranks, respectively. The figures show that there is little or no difference in the relationship between the two income measures for both levels of schooling in the U.S. and for college attendance in Denmark. For rates of high school completion in Denmark, however, we see that the inclusion of public benefits results in a steeper negative slope at the very lowest levels of incomes. The reason for this anomaly is that a small share of those with close to zero wage earnings and public transfers in Denmark live from capital income or profits from businesses instead. The educational outcomes of this group are very different from those experienced by children from the remaining low-income families.
} 


\subsection{Controlling for Skills Formed in Early Adolescence, Family Characteristics, and Sorting of Children into Schools by Parental Income}

This section adjusts the figures displayed previously in this section by controlling for cognitive and non-cognitive skills, measures of family background, and measures of school characteristics. Doing so significantly reduces the income and wealth differentials, with early adolescent measures of cognitive and non-cognitive skills playing a major role.

Table 4 presents linear regression estimates of parental log income and wealth on children's high school completion and college attendance for the U.S. and Denmark. The estimates can thus be interpreted as elasticities ${ }^{46}$ In the upper panel of the table we present estimates with high school completion as the outcome, and in the lower part of the table we present the result with college attendance as the outcome. Below each set of estimates for Denmark and the U.S., we show differences in coefficients between the two countries and the associated $p$-values for tests of differences. The first column of the table shows the unadjusted linear estimates corresponding to Figure A14, and in the subsequent three columns we gradually increase the conditioning set.

From column 1 of the table, we see that parental income and wealth are strongly associated with children's high school completion and college attendance in the U.S. and in Denmark. As shown in Figure A14, parental income and wealth gradients for children's high school completion are significantly higher in Denmark, while only the gradient for wealth differs for college attendance.

\footnotetext{
${ }^{46}$ Web Appendix Table A16 shows the corresponding regression coefficients for parental income and wealth ranks for children's high school completion and college attendance for child skills at age 15, family background, and school quality.
} 
The second column presents the associations while controlling for child's level of cognitive and non-cognitive skills measured at age 15-16. In comparison to the estimates from the first column, the income and wealth gradients for high school completion and college attendance are substantially reduced. Thus, the relationship between parental resources and child education is to a large degree mediated by levels of cognitive and non-cognitive skills at earlier ages. While the upper panel shows that the coefficients for income and wealth still differ between Denmark and the U.S. for high school completion, the estimates in the second column of the lower panel show that there are no significant differences between Denmark and the U.S. for either income or wealth gradients in college attendance.

Even though cognitive and non-cognitive skills are highly predictive of educational attainment in both Denmark and the U.S., cross-country differences in these skills do not explain the entire relationship between parental resources and educational attainment. When we extend the analysis in the third column by adding measures of parental background (education/family status) to the measures of child skills, the relationship between parental financial resources and child education weakens further ${ }^{47}$ Again, we find that associations between parental income and wealth on the one hand and children's probability of high school completion on the other, is stronger in Denmark compared to the U.S. We find no cross-country differences in the estimated relationships for college attendance.

Cognitive and non-cognitive skills and parental/family background play similar roles in mediating the relationship between parental financial resources and children's educational outcomes in both countries. However, other differences remain in comparing educational income and wealth gradients in the two countries. For example, Denmark and the U.S. differ in the variability of school quality. Differences between the quality of public and private schooling

\footnotetext{
${ }^{47}$ Parental background variables are: child gender (0/1), immigrant/minority (0/1), urban region (0/1), number of siblings, mother's age at birth, and mother's years of schooling.
} 
likely depend on overall resources devoted to public schools - a major difference between the two countries. Denmark spends a far greater fraction of its GDP on public education than the U.S. ${ }^{48}$ Yet school resources and peer characteristics still vary by parental resources in Denmark, suggesting similar relationships between measures of schooling quality and family characteristics across the two countries. We present a preliminary exploration of these relationships for Denmark in this section, where we establish that a school quality gradient also exists in Denmark. However, due to lack of data, we are unable to test for differences in the distributions of school quality.

In the final column of Table 4, we show estimates of the association between children's education and parental income and wealth conditioning on the child's level of skills at ages 15-16, family background measures, and school characteristics measured in the primary school years. The gradients in parental income and wealth are substantially reduced because quality measures for primary school predict later educational attainment 49 For Denmark, there is no remaining significant relationship between parental resources and children's education, while for the U.S., a small relationship remains. Moreover, we only find one statistically significant cross-country difference at a $5 \%$ level between the gradients of children's rates of high school completion and college attendance as functions of parental financial resources, and generally none of the estimates differ qualitatively between Denmark and the U.S.

\footnotetext{
${ }^{48}$ See Organisation for Economic Co-operation and Development (2014) for an overview of public and private resources devoted to primary, secondary, and tertiary education, and Table A13 in the Web Appendix.

${ }^{49}$ As data sources from the two countries differ (Denmark is register data and U.S. is survey data), we proxy school characteristics by aspects that are not directly comparable. For the U.S., we use parents' ratings of their child's school and for Denmark, we use average characteristics of earlier cohorts in a given school. The results are used to illustrate that substantial sorting takes place in both Denmark and the U.S. and that this sorting coincides with parental resources. Hence, once we also condition on our school characteristics measures, the income and wealth gradients in children's schooling are reduced further. Importantly, the results are not causal, nor do they identify the impact of school quality on later education.
} 
Table 4: Regression coefficients for high school completion and college attendance on parental resources by different conditioning sets

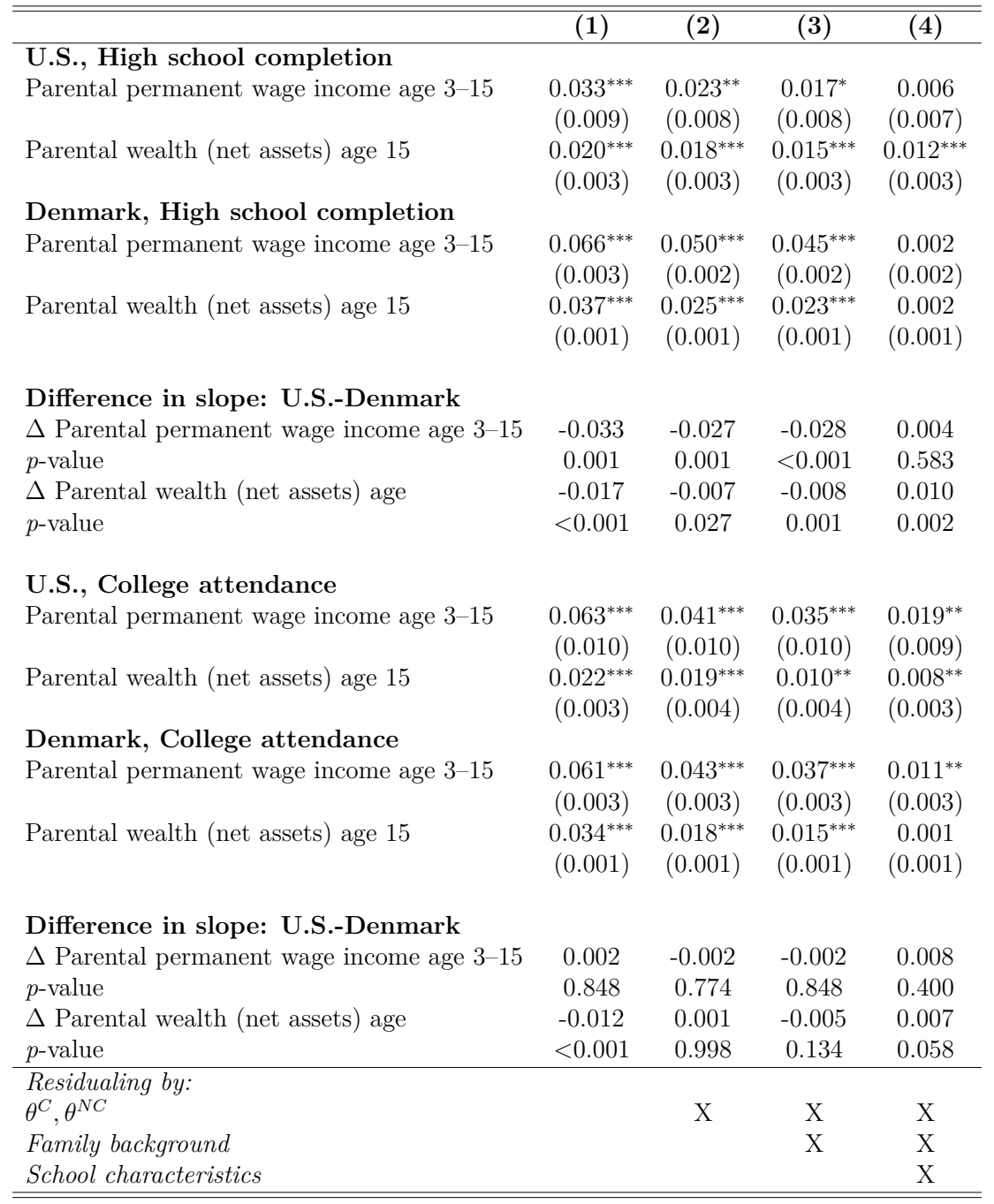

Note: Table shows regression coefficients of parental permanent wage income and wealth on children's high school completion and college attendance for increasing conditioning set with skills, family background, and school characteristics. Table constructed using data from the CNLSY for the U.S./administrative register data on the full cohort born in 1987 for Denmark. The table shows $p$-values from tests of equal slope-coefficients against a two-sided alternative.

Family background variables: child gender (0/1), immigrant/minority (0/1), urban region (0/1), siblings, mother's age at birth, and mother's years of schooling.

School characteristics for U.S. include: grade for how teachers care about students, grade for whether school is considered safe, a dummy for whether child feels peer pressure to work hard, a dummy for whether child feels peer pressure to skip school, a dummy for whether child has received sex education in school, and a dummy for whether child attends private school. School characteristics for Denmark include: for each school, the means of previous cohort's mother's age at birth, mother's high school completion, and mother's college attendance, high school completion, and college attendance.

Observations: U.S. 3,268; Denmark 39,539.

${ }^{+}: \mathrm{p}<0.1,{ }^{*}: \mathrm{p}<0.05,{ }^{* *}: \mathrm{p}<0.01,{ }^{* * *}: \mathrm{p}<0.001$. 


\subsection{Nonlinear Elasticities Between Children's Education and Parents' Income}

The results reported in Table 4 are average estimates for the two populations in question. As we argued for income mobility, it is likely that any benefits from the Scandinavian welfare states accrue to the least advantaged. To allow for nonlinearities in the association between children's education and parent's gross income including transfers we repeat the analysis from Section 2.4 and estimate local linear regressions of children's high school completion, college graduation on parents' log income. Using the same data and estimation strategy as was used in Section 2 . Figures $7 \mathrm{a}, \mathrm{b}, \mathrm{d}$, and e examine the nonlinearities in the elasticities between children's high school/college completion and parental gross income including transfers. Figures 7f and 7f show the cross-country differences between the estimated elasticities 50

The figures show strong nonlinearities within countries and across educational levels. Elasticities for high school completion vary between 0 and 0.3 in Denmark, and 0 and 0.12 in the U.S. For college graduation, the nonlinear relationship with parental income is even more apparent. In both countries, elasticities vary between approximately $0.10-0.15$ for low-income families and $0.40-0.45$ for families with an average annual income of around $\$ 125,000$. Yet, as shown in Figures 7fc and 7f, there is not any substantial difference in educational mobility between Denmark and the U.S. When differences arise, they often do not favor Denmark. Moreover, the shape of the cross-country differences in educational mobility across parents' total gross income do not show any strong nonlinear pattern favoring the least advantaged in Denmark relative to the least advantaged in the U.S.

\footnotetext{
${ }^{50}$ Figure A21 in the Web Appendix shows the equivalent results using wage earnings and not gross income including transfers. Figures A22 A23 show nonlinear estimates of children's education (high school completion, college graduation, master degree, highest grade completed) on parents' average highest grade completed. The figures show nonlinearities across different levels of parental education and differences between the various measures of children's education. However, the figures show no patterns that favor educational mobility in Denmark over that in the U.S.
} 


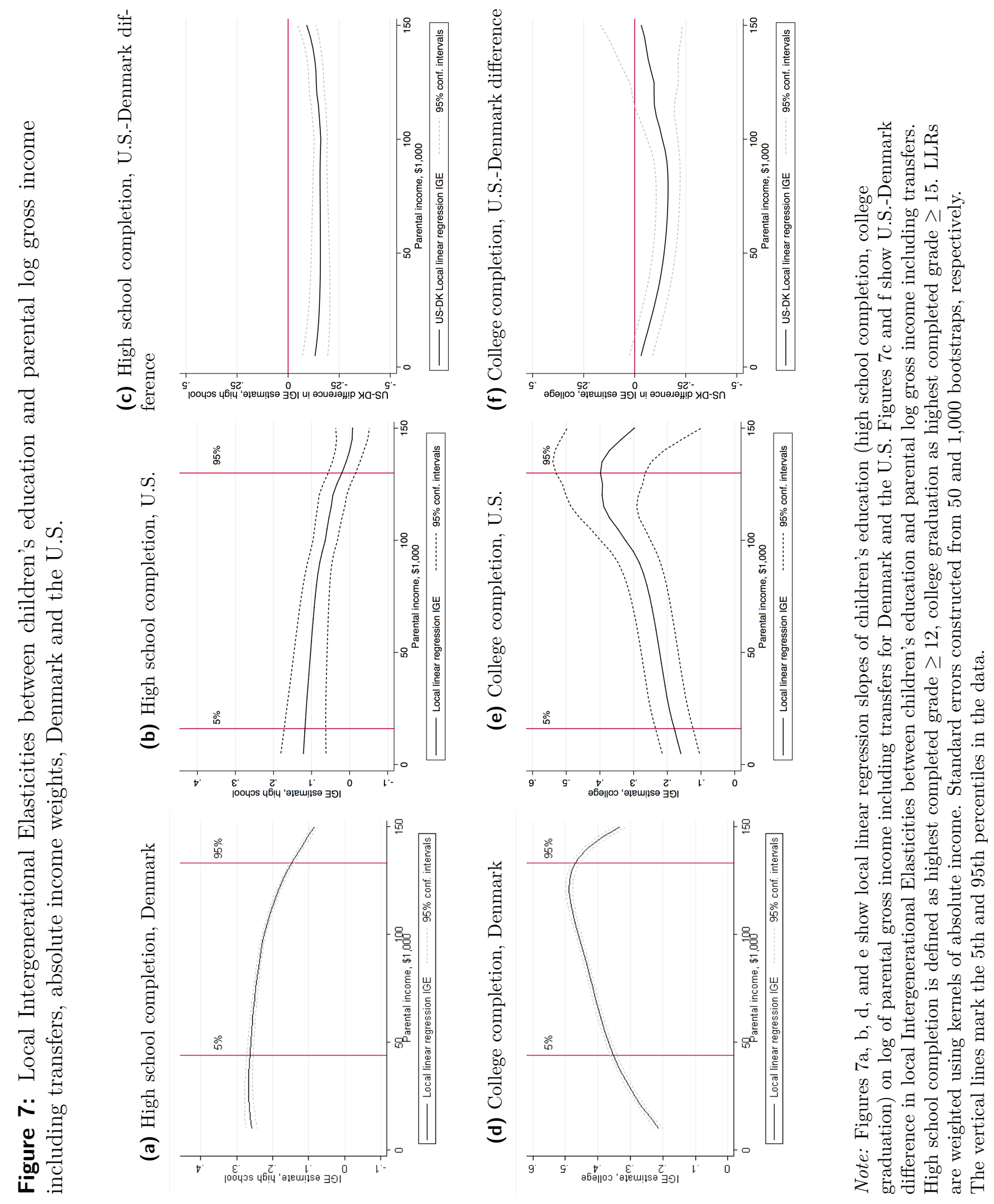


These results also shed light on the likely relationship between credit constraints in the adolescent years and educational attainment, which is investigated by a large body of literature 51 That literature is often inconclusive as it does not control for the other parental characteristics associated with income. A related strand of literature investigates the effects of tuition and restrictions to funding of education $\sqrt[52]{2}$ Even though we do not explicitly address this issue, our results are consistent with the evidence that it is not income during the adolescent years that matters, but investments as crystallized in cognitive and non-cognitive skills and longer term family background factors that drive these associations. 53 Our analysis shows that most of the association between high school completion and parental resources, and around half of the association between college enrollment and parental resources, is accounted for by differences in children's cognitive and non-cognitive skills and family background in early adolescence 54 Although the U.S. and Denmark constitute two opposite poles in terms of tuition costs, the income and wealth gradients in high school completion and college enrollment do not differ substantially between the two countries.

In conclusion, despite the higher cognitive scores for the disadvantaged and the lower pecuniary costs of education in Denmark, our analysis in this section together with several other supplementary data sources (see Web Appendix Sections A.2 and B.4 Organisation for Economic Co-operation and Development, 2014, Hertz et al. 2008) all point in the same direction. There are only few noteworthy differences in educational mobility between the U.S. and Denmark, and certainly nothing that can explain the differences in income and wage earnings mobility reported in Section 2, This analysis raises an important question: Are

\footnotetext{
${ }^{51}$ See the summary of the literature in Heckman and Mosso (2014) and Lochner and Monge-Naranjo (2016).

52 Cameron and Taber (2004), Carneiro and Heckman (2002), and Keane and Wolpin (2001) find little evidence of this relationship as opposed to Bailey and Dynarski (2011), Belley and Lochner (2007), and Lochner and MongeNaranjo (2012), who report stronger evidence of credit constraints to, for example, college enrollment.

${ }^{53}$ This is consistent with the evidence reported in Cameron and Heckman (2001).

${ }^{54}$ This finding mirrors the analysis of Heckman (2011) in showing the importance of cognitive and non-cognitive skills in explaining minority-majority differences in college attainment in the U.S.
} 
there factors embedded in the Scandinavian welfare state which reduce incentives to pursue education and thus educational mobility? We will discuss and investigate this in the next subsection.

\subsection{Welfare Levels and Educational Incentives}

It is well established that the economic returns to education are substantially lower in Denmark and the other Scandinavian countries than in the U.S. (see, e.g., Fredriksson and Topel, 2010. Harmon et al., 2003). Two mechanisms leading to this difference are wage compression and the high levels of welfare benefits observed in Scandinavia. As noted in Edin and Topel (1997) and Fredriksson and Topel (2010), incentives to pursue education diminish as returns to education decrease and welfare benefits increase. In this subsection we establish an empirical relationship between educational attainment and potential public benefits in Denmark. We refer the reader to Web Appendix Section B, and Edin and Topel (1997), Fredriksson and Topel (2010), Freeman et al. (2010), Rosen (1997), and Tranæs (2006) for discussions and descriptive evidence of the differences between the income and employment prospects of un- or low-skilled individuals in Denmark and the U.S., and the relationship between public sector employment, public benefits, and the wage floor in Denmark. In Web Appendix Section B we further show that incomes are compressed in the tails of the educational and income distributions in Denmark. Hence, the lower returns to education in Denmark compared to the U.S. do not stem from cross-country differences in educational tracks which could cloud the relationship between years of schooling and income.

Figure 8 illustrates the issue at hand. The figure shows mean pre-tax wage earnings measured in 2010-2012 for the cohorts born 1973-1975 in Denmark, by highest completed educa- 
tion 55 together with horizontal lines indicating the 2011 maximum unemployment insurance benefits and the social assistance levels in Denmark. From the figure it is evident that for individuals with the lowest levels of education, average wage earnings barely exceed maximum social assistance levels. Even as one climbs the educational ladder, it is not until college completion that wage earnings are twice the size of social assistance. The progressivity of the Danish tax system only makes this pattern more pronounced.

While the relationship between returns to education, public benefits, and educational attainment has been discussed in the literature we cite, there is little causal evidence. Figure 9 provides the first evidence of such a causal relationship by illustrating the response to two reforms of social assistance levels for youths passed in Denmark in 1991 and 1992/1993, respectively, that increased the incentive to be enrolled in an education relative to dropping out.56 The first reform raised the minimum age of eligibility for full social assistance from age 20 to age 21 and the second reform raised the minimum age for receipt from 21 to 25 . Below the minimum age, individuals are only entitled to 'youth assistance' (ungdomsydelse), which is approximately $50 \%$ of the full SA level and equal to the public education grant (SU) ${ }^{57}$

Figure 9 shows rates of enrollment in any education measured on a weekly basis from age 19 to age 26 for the cohorts born in 1969-1974. In Figure 9a, we plot enrollment rates for individuals who were 20 and 21 years old at the timing of the 1991 reform that raised the minimum age from 20 to 21 . The figure shows that enrollment rates were similar at younger

\footnotetext{
${ }^{55}$ In this analysis we use the data which was introduced in Section 2.1

${ }^{56}$ See https://www.retsinformation.dk/Forms/R0710 .aspx?id=53834, https://www.retsinformation.dk/Forms/R0710.aspx?id=53834,

and https://www.retsinformation.dk/Forms/R0710.aspx?id=53886 (accessed 4-1-2016) for the specific bills in question.

57 Jonassen (2013) studies behavioral responses around age 25. He finds that take-up of social assistance increases substantially once benefits increase to full level at age 25. Furthermore, he finds no evidence of substitution between social assistance and public education grant at age 25. This contrast to our results suggests that the link between social assistance and education is mainly present at lower-tier educations (i.e., for low-skilled individuals) which would have been completed at age 25 in any case.
} 
ages, but at the exact timing of the reform the two groups diverged and enrollment rates became approximately 2-3\%-points higher for the affected group who were 20 years old at the timing of the reform, relative to the unaffected group who were 21 years old.

Figure 9b shows a similar response around the timing of the 1992/1993 reform that raised the minimum age from age 21 to 25 . The figure shows enrollment rates for individuals who were 20-23 years old at the timing of the reform. We see that the groups had similar trajectories prior to the change but diverged once the minimum age was raised. Those affected at age 20 broke away from the three remaining cohorts at age 20. Those affected at age 21 broke away from the two remaining cohorts at age 21 . Those affected at age 22 diverged at this exact age from those who were affected at age 23 .

The results presented here establish a negative relationship between educational enrollment and the level of public benefits, albeit with two caveats. First, it is beyond the scope of this paper to estimate the underlying behavioral parameters - we strongly encourage future research to explore this relationship further. Second, we neither have precise estimates of the potential gains from the greater equality in childhood investments and fewer pecuniary costs of education in Denmark than in the U.S., nor the disincentives for educational attainment that wage compression and public benefits constitute. Hence, we cannot determine whether the similarities in educational mobility in the two countries occur because the effects offset each other, though we find this to be a plausible explanation given the evidence at hand. 
Figure 8: Average wage earnings and potential benefits levels, cohorts 1973-1975 in 2010-2012, Denmark
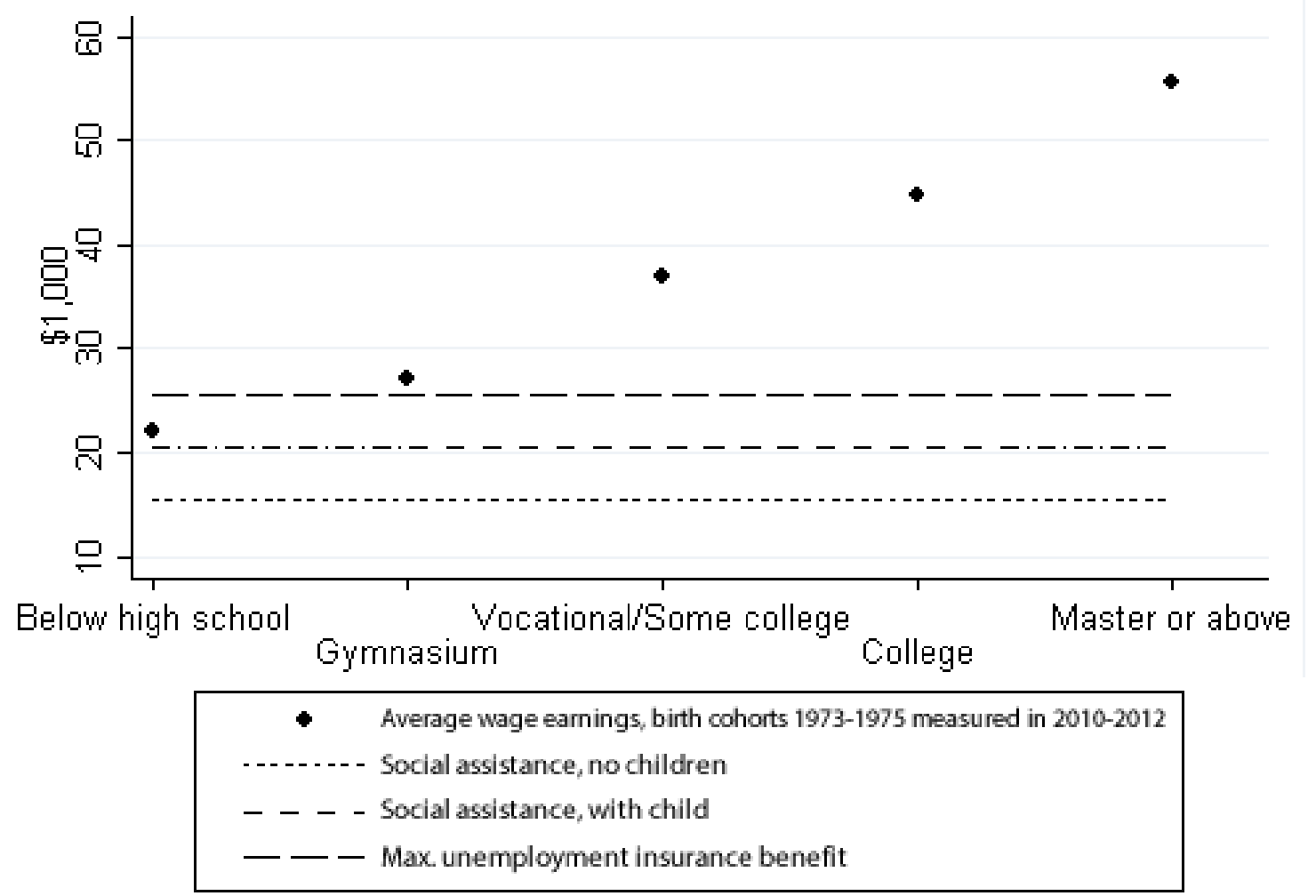

Note: Figure shows average wage earnings per year from 2010 to 2012 for the cohorts born in 1973-1975 in Denmark. The figure also shows maximum unemployment insurance benefits, social assistance level for individuals with children (extra benefit for second child applies), and social assistance level for individuals without children. The horizontal lines are the raw benefits and do not include means tested daycare slots and other types of benefits. Average wage earnings are estimated from the full sample and are not conditional on employment.

Education: 'Below high school' is years of schooling $<12$. Gymnasium is defined as 12 years of schooling and a gymnasium or HF degree (see discussion of HF in footnote 39p. 'Vocational/Some college' is defined as $12<$ years of schooling $<15$, or $12 \leq$ years of schooling $<15$ and a vocational training degree. 'College' is defined as $15 \leq$ years of schooling $<17$. 'Master or above' is defined as years of schooling $\geq 17$ which corresponds to at least a masters degree from a university.

Wage earnings: Taxable wage earnings and fringes, labor portion of business income, and non-taxable earnings, severance pay, and stock-options.

Unemployment insurance benefits: Eligibility is based on previous employment and membership of unemployment insurance fund (insurance is tax-deductable and benefits are subsidized by the public sector). The figure reports the maximum level available. Below this level, unemployment insurance benefits replace wage earnings by a rate of $90 \%$.

Social assistance: Means tested (on household level) such that income earned is deducted 1:1 from benefits. Levels differ by whether recipients have children or not. 

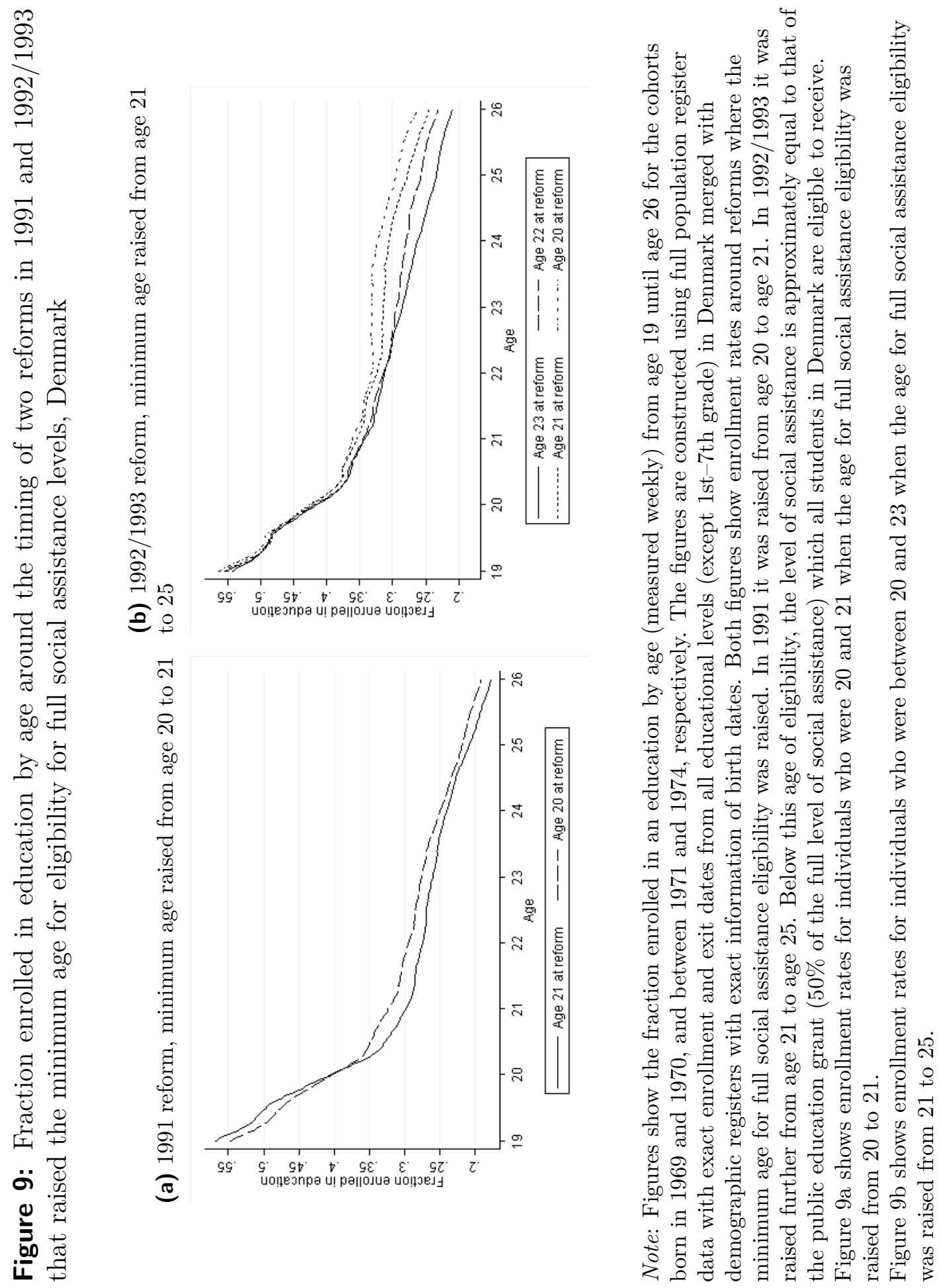


\subsection{Neighborhood Sorting of Children by Family Background}

Neighborhood sorting by family socioeconomic status is prevalent in each country. Public schooling in Denmark is universal and attempts to offer all children equal amounts of high quality schooling. This policy may be disequalizing because children with early advantages accumulate skills at a higher rate while in school ${ }^{58}$ High levels of equal investments in schooling for all children amplify initial gaps between advantaged and disadvantaged children. This is a consequence of static complementarity between investments and child skill levels at each age, reinforced by increasing complementarity between investments and skill levels as children age. ${ }^{59}$ Figures 10 and 11 show that, in Denmark, different measures of parental resources correlate with the school and peer quality of public schools ${ }^{60}$ and thus, investments in children through the public schools tend to increase with parental income 61

${ }^{58}$ Heckman and Mosso (2014) present evidence supporting disequalization.

${ }^{59} \overline{\text { Cunha and Heckman }}$ (2007), Carneiro et al. (2013), and Heckman and Mosso (2014) discuss static and dynamic complementarity. Static complementarity is described by the "Matthew Effect:" To those who have, more is given. Dynamic complementarity is the effect of investments at one age on building complementarity at later ages.

${ }^{60}$ Danish schools receive higher rates per student for special needs education, but not based on overall resource level of catchment area. See the Public School Law (https: //www.retsinformation.dk/Forms/r0710.aspx?id=163970).

${ }^{61} \mathrm{~A}$ vast literature has described the significant impacts of school and peer quality on educational outcomes and income. See Sacerdote (2011) for examples. 
Figure 10: Peers' skill levels across parental income rank, Denmark

(a) Mean of birth endowments for peers in preschool

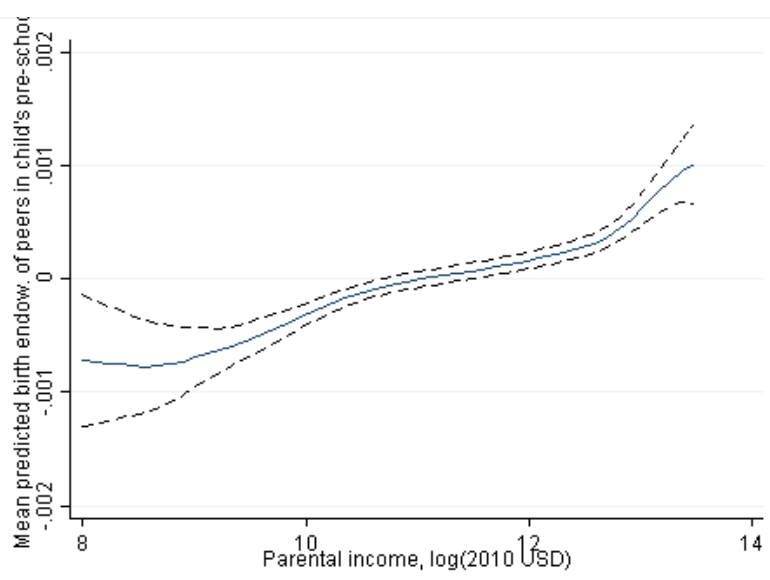

(b) Mean of cog. skills at ages $15-16$ for peers in lower secondary school

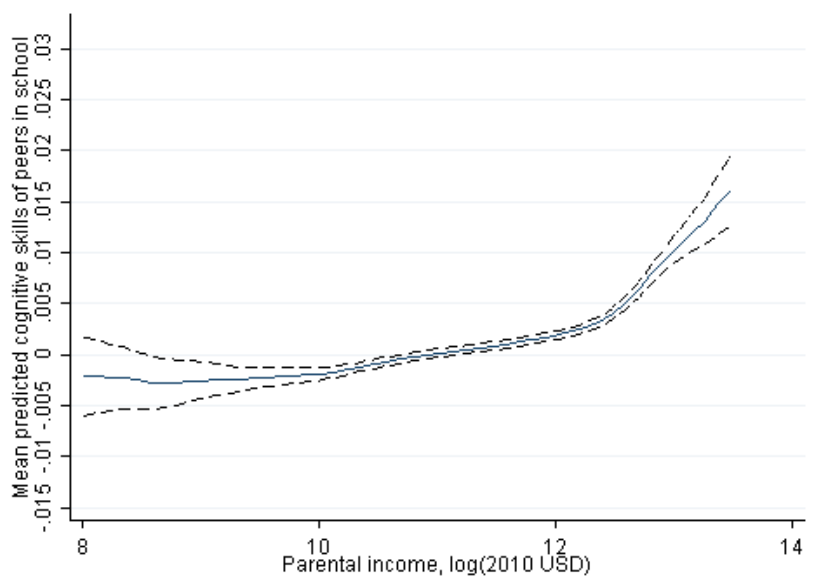

(c) Mean of noncog. skills at ages 15-16 for peers in lower secondary school

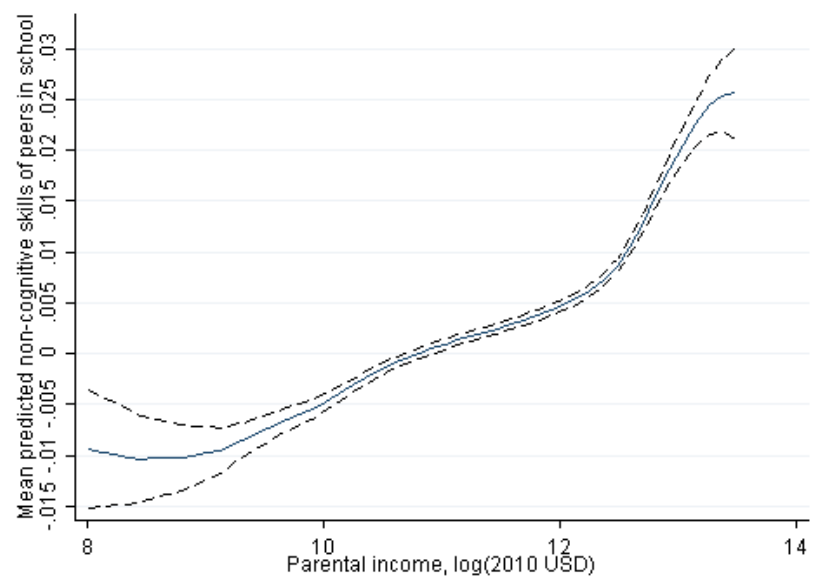

Note: Figure shows school 'leave-one-out' means of predicted cognitive and non-cognitive skills, from the estimated measurement system, using the cohort born in 1987 in Denmark. Mean of peers' birth endowments in preschool are calculated using the 1995 birth cohort. The skills are anchored to $\mathrm{P}$ (high school completion) and the y-axis may be interpreted as such. Hence, a difference of 0.02 from the $\log$ (income) of 10 to $\log$ (income) of 11 for non-cognitive skills implies that the mean level difference in non-cognitive skills for peers of children whose parents' $\log$ (income) equal 10 and 11, respectively, are associated with a $2 \%$-point difference to the likelihood of completing high school. We use birth weight, gestational length, and length at birth to estimate birth endowments. We use exam grades on math and physics to estimate cognitive skills and grades on organization/neatness to estimate non-cognitive skills. 
Figure 11: Peers' skill levels across property value in catchment area of lower secondary school, Denmark

(a) Mean of birth endowments for peers

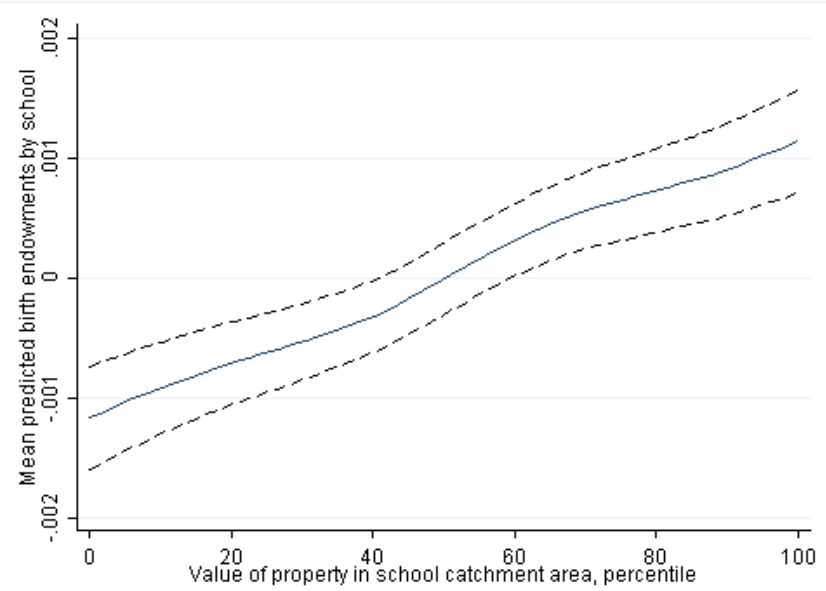

(b) Mean of cognitive skills at ages $15-16$ for peers

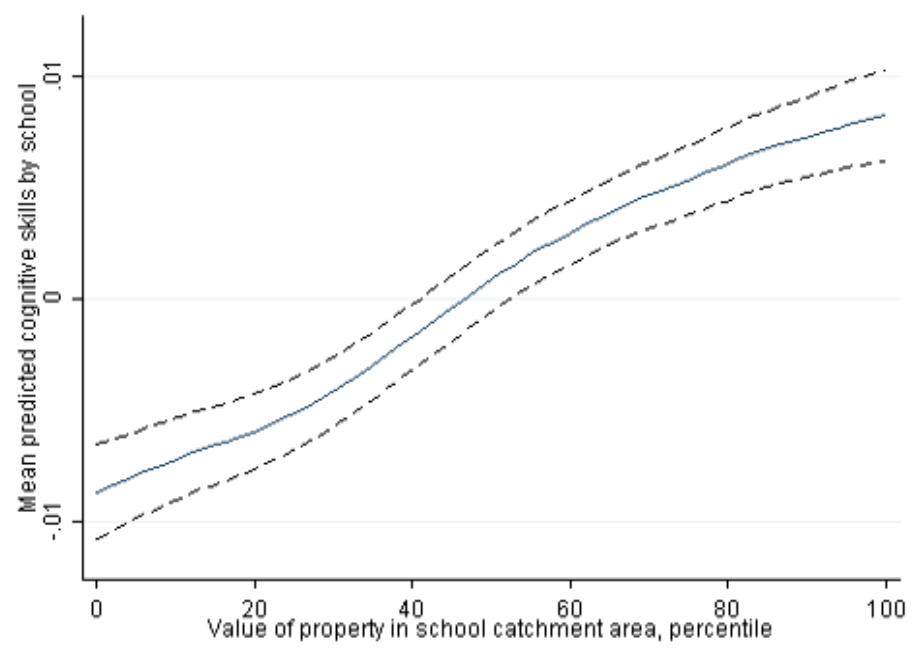

(c) Mean of non-cognitive skills at ages $15-16$ for peers

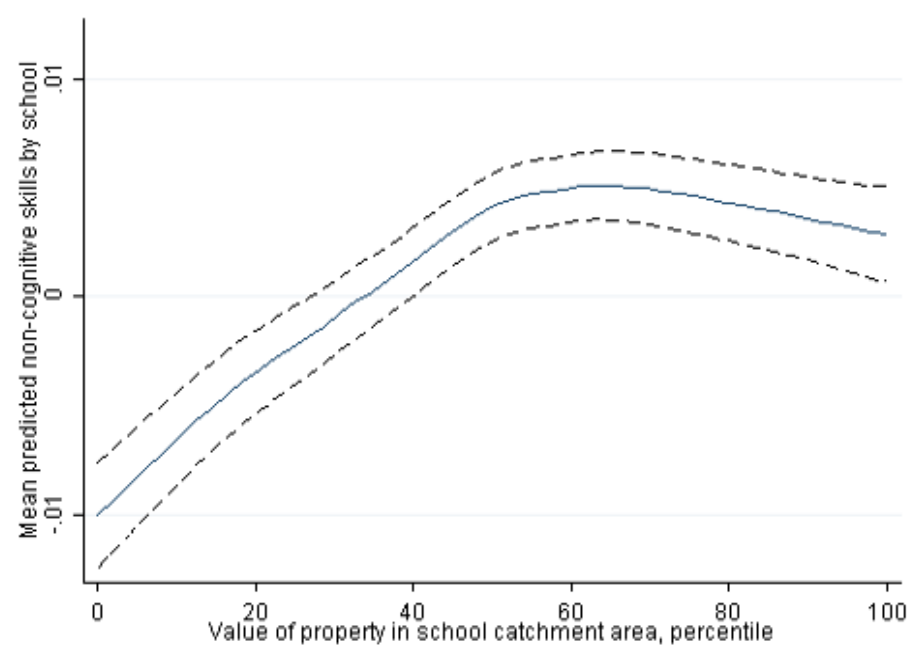

Note: Figure shows school 'leave-one-out' means of predicted birth endowments and cognitive and non-cognitive skills, from the estimated measurement system, using the cohort born in 1987 in Denmark. The skills are anchored to P(high school completion) and the y-axis may be interpreted as such. Property value is measured as mean valuation of owned property (from Statistics Denmark and Danish national tax authorities) in a given catchment area. Hence, a difference of 0.02 from the 1st to the 100th percentile for cognitive skills implies that the mean level of cognitive skills for peers of children whose parents own property in the most expensive school catchment area are associated with a $2 \%$-point higher likelihood of completing high school. We use birth weight, gestational length, and length at birth to estimate birth endowments. We use exam grades on math and physics to estimate cognitive skills and grades on organization/neatness to estimate non-cognitive skills. 
In a similar vein, Figures $12 \mathrm{a}$ and $\mathrm{b}$ show variation in average high school completion and college attendance rates across schools. In some schools, only $50 \%$ of students complete high school and $10 \%$ of students attend college, respectively, while in other schools, all students complete high school and $80 \%$ attend college. The figures also show large differences in average parental gross income across schools. The differences correlate strongly with the later educational attainment of students. Figures $12 \mathrm{c}$ and d plot the average high school completion and college attendance rates against the school mean peer parental gross income and highest grade completed. The figures show that the average educational attainment of a 9th grade student is strongly positively correlated with peer family income and education.

Catchment areas for public institutions that limit peers to sort with certain income groups and equal public investments tend to favor children from high income families 62 The strong relationship in Denmark between educational attainment and family background could arise solely as a result of neighborhood sorting on the basis of family income and wealth.

We lack comparable information for the U.S. If in fact sorting is equally strong in the two countries, this factor may be an important contributor to explaining the near equality of educational IGEs in both countries. Residential sorting may help undo the benefits of the Scandinavian welfare state. We leave this topic for future research.

Certainly equality of opportunity is not present in Denmark. Figure 13 shows socioemotional ratings measured at age 7 and 12, and cognitive and language test scores measured at age 12 by parental permanent gross income for Danish children. For all three measures, the average gaps between the most disadvantaged children and the most advantaged children are around 0.5 of a standard deviation. Thus, as evidenced by the figure and our analysis earlier in this section, substantial skill gaps throughout childhood and adolescence remain in Den-

\footnotetext{
${ }^{62}$ See Black and Machin (2011) for a review of this literature. Tiebout (1956) and Black (1999) shows that housing prices are affected by school quality. More related to the Danish case, Machin and Salvanes (2016) provide recent evidence on this issue from Norway.
} 
mark. While the Scandinavian welfare state invests heavily in children throughout childhood and redistributes income (consumption) during adulthood, it has not eradicated the strong influence of parents and early childhood conditions. As a consequence of the complementarity between skills and investments, later life universal schooling investments during childhood or adolescence may be ineffective in reducing gaps between advantaged and disadvantaged children.

\section{Limitations, Future Directions, and Open Ques- tions}

Before concluding, we discuss some limitations of this study. First, like much of the empirical literature on social mobility, we report empirical relationships across generations. Our discussion emphasizes the need for a clearer theoretical framework to disentangle the effects of different income sources (wage earnings, profits, capital, public transfers, and taxation) and mechanisms through which they are related across generations (the dynamics of parental and public investments/human, monetary, and physical capital transmission).

Second, our analysis measures parental income as permanent income during a child's primary and secondary schooling ages. Permanent family income over the life cycle of children has been shown to account for most of the variation in the relationship between family income and children's schooling (Carneiro and Heckman, 2002). Yet it may be that the pivotal differ- 
ences between the U.S. and Denmark materialize at early ages ${ }^{63}$ Low-income parents may be constrained in making early lifetime investments in the U.S. but not in Denmark ${ }^{64}$

Third, any attempt to capture a country's level of intergenerational mobility and the relationship between parental and child outcomes by a few point estimates is bound to be unsatisfactory. While the estimation of nonlinear IGEs is a step in the right direction, other empirical strategies might be used. One strategy estimates local rank-regressions, where the IGE is found by minimizing the product of ranked residuals, thus putting less weight on extreme observations and more weight on mid-rank observations. Our empirical analysis of rank-regressions is consistent with our analysis of nonlinear IGEs. There is curvature in the estimated relationships at the top and at the bottom of the income distribution 65 Another method is copulas, which may be particularly useful in the present case of describing the dependence between parental and children's income because tail dependence in income distributions is notoriously difficult to determine 66

There are a number of aspects of inequality that we have not analyzed. We have not addressed issues pertaining to in-kind transfers, health, and access to health care, but only to inequality in terms of skill formation, educational attainment, and income. A more comprehensive analysis would be desirable.

\footnotetext{
${ }^{63}$ In a similar vein, in our analysis of income mobility, we have chosen an age range to measure income which should proxy lifetime income closely. Yet we still only provide a snapshot of income mobility under the assumption of homogenous time preferences. Educational attainment and time preference correlate (Oreopoulos and Salvanes, 2011). In consequence, intergenerational income mobility estimates reported here and in the remaining literature may be biased if income at older ages should receive less weight than income at early ages for individuals without college degrees and vice versa. One possible next step would be to create a Generalized Intergenerational Income Elasticity which evaluates the entire stream of lifetime earnings for parents and children, allowing for differential time preferences. Even better would be to form the value functions of lifetime earnings (see, e.g., Hai and Heckman 2016).

${ }^{64}$ See the discussion in Lochner and Monge-Naranjo (2016).

${ }^{65}$ See Section D of the Web Appendix for a brief outline.

${ }^{66}$ See Section $\bar{E}$ of the Web Appendix for a brief introduction and examples.
} 


\section{Conclusion}

Academics and policy makers around the world point with admiration to Scandinavia as a model for reducing inequality and promoting social mobility without sacrificing economic efficiency or growth. This paper takes a first step towards investigating in what dimensions and for what reasons Scandinavia is more effective in promoting social mobility.

Despite Denmark's far more generous welfare state, its extensive system of preschools, and its free college tuition, the family influence/child education relationship is very similar to that of the U.S. In both countries, much of the average association between parental resources and the educational attainment of children can be explained by factors set in place by age 15, including child skills. However, distributions of cognitive test scores of disadvantaged Danish children are much better than those of their counterparts in the U.S.

The failure to promote greater educational mobility in spite of providing generous social services is most likely rooted in the welfare state. Our findings point to wage compression and the higher levels of welfare benefits as being counterproductive in providing incentives to pursue education. The low returns to education observed in Denmark, in particular at the lower levels of education, help explain the disconnect between the egalitarian childhood policies in Denmark and the roughly equal levels of educational mobility in Denmark and the U.S. The sorting of families into neighborhoods and schools by levels of parental advantage is likely

another contributing factor. While the Danish welfare state may mitigate some childhood inequalities, substantial skill gaps still remain.

While patterns of educational attainment are similar across the two countries, the relationships linking skills and income differ greatly. The IGE estimates of income mobility-used as evidence for Scandinavia's high social mobility - are very sensitive to the choice of income measure analyzed. Using total income potential excluding public transfers as a measure of income, 
there are fewer differences between estimated IGEs for Denmark and the U.S. than previously portrayed. Considering wage earnings or wage earnings plus public transfers, average income mobility is higher in Denmark than in the U.S. We find evidence of strong nonlinearities in measures of intergenerational income mobility. Differences in Danish-U.S. income mobility favor Denmark (i.e., produce lower local IGEs) at higher levels of parental income and at very low levels of parental income. The education-family background gradients are also nonlinear in both countries but do not favor Denmark at either tail of the parental income distribution.

This paper sends a cautionary note to the many enthusiasts endorsing the Scandinavian welfare state. We make no statements about the optimality and fairness of the U.S. and Danish systems from a philosophical or social choice point of view. The Danish welfare state clearly boosts the cognitive test scores of disadvantaged children compared to their U.S. counterparts. But test scores are not the whole story, or even the main story of child success, despite the emphasis on them in popular discussions. Moreover, substantial gaps in test scores remain across social groups within Denmark.

Differences in income mobility between Denmark and the U.S. also arise from wage compression in the Danish labor market, the progressivity of the Danish tax-transfer system, and the increasing college premium in the U.S. and the rise in inequality there. These factors drive the higher population average income mobility in Denmark and equalize post-tax consumption possibilities. They also discourage educational attainment in Denmark. Along with neighborhood sorting, they explain the similarity in the influence of family background on educational attainment in the two countries.

The U.S. excels in incentivizing educational attainment. The Danish welfare state promotes cognitive skills for the disadvantaged children. Policies that combine the best features of each system would appear to have the greatest benefit for promoting intergenerational mobility in terms of both income and educational attainment. 


\section{References}

Aaberge, R., A. Björklund, M. Jäntti, M. Palme, P. J. Pedersen, N. Smith, and T. Wennemo (2002, December). Income inequality and income mobility in the Scandinavian countries compared to the United States. Review of Income and Wealth 48(4), 443-469.

Aaberge, R., T. Wennemo, A. Björklund, M. Jäntti, P. J. Pedersen, and N. Smith (2000, March). Unemployment shocks and income distribution: How did the Nordic countries fare during their crises? Scandinavian Journal of Economics 102(1), 77-99.

Bailey, M. J. and S. M. Dynarski (2011, December). Gains and gaps: Changing inequality and U.S. college entry and completion. Working Paper 17633, National Bureau of Economic Research.

Baily, M. N. (2016, March). What Sanders gets right and wrong about Denmark. Online article, Inside Sources, http://www.insidesources.com/what-sanders-gets-right-and-wrongabout-denmark/.

Belley, P. and L. Lochner (2007, December). The changing role of family income and ability in determining educational achievement. Journal of Human Capital 1(1), 37-89.

Berligske Tidende (2015, April). Studerende består, selvom de burde dumpe. Website: http://www.b.dk/nationalt/studerende-bestaar-selvom-de-burde-dumpe.

Björklund, A. and M. Jäntti (1997, December). Intergenerational income mobility in Sweden compared to the United States. American Economic Review 87(5), 1009-1018.

Björklund, A. and M. Jäntti (2011). Intergenerational income mobility and the role of family 
background. In W. Salverda, B. Nolan, and T. M. Smeeding (Eds.), Oxford Handbook of Economic Inequality, Chapter 20, pp. 491-521. Oxford, UK: Oxford University Press.

Björklund, A., J. Roine, and D. Waldenström (2012, June). Intergenerational top income mobility in Sweden: Capitalist dynasties in the land of equal opportunity? Journal of Public Economics 96(5-6), 474-484.

Black, S. E. (1999, May). Do better schools matter? Parental valuation of elementary education. Quarterly Journal of Economics 114(2), 577-599.

Black, S. E. and P. J. Devereux (2011). Recent developments in intergenerational mobility. In O. C. Ashenfelter and D. Card (Eds.), Handbook of Labor Economics, Volume 4, Part B, Chapter 16, pp. 1487-1541. Amsterdam: Elsevier B. V.

Black, S. E. and S. Machin (2011). Housing valuations of school performance. In E. A. Hanushek, S. Machin, and L. Woessmann (Eds.), Handbooks of the Economics of Education, Volume 3, Chapter 10, pp. 485-519. Amsterdam: Elsevier B. V.

Blanden, J. (2013, February). Cross-country rankings in intergenerational mobility: A comparison of approaches from economics and sociology. Journal of Economic Surveys 27(1), $38-73$.

Blanden, J., R. Haveman, T. Smeeding, and K. Wilson (2014, September). Intergenerational mobility in the United States and Great Britain: A comparative study of parent-child pathways. Review of Income and Wealth 60(3), 425-449.

Bonke, J., M. A. Hussain, and M. D. Munk (2005). A comparison of Danish and international findings on intergenerational earnings mobility. Working Paper, Social Forsknings Instituttet. 
Borghans, L., B. H. H. Golsteyn, J. J. Heckman, and J. E. Humphries (2011a, August). Identification problems in personality psychology. Personality and Individual Differences 51(3: Special Issue on Personality and Economics), 315-320.

Borghans, L., B. H. H. Golsteyn, J. J. Heckman, and J. E. Humphries (2011b). IQ, achievement, and personality. Unpublished manuscript, University of Maastricht and University of Chicago (revised from the 2009 version).

Boserup, S., W. Kopczuk, and C. T. Kreiner (2013). Intergenerational wealth mobility: Evidence from Danish wealth records of three generations. Dissertation chapter, University of Copenhagen.

Bratsberg, B., K. Røed, O. Raaum, R. Naylor, M. Jäntti, T. Eriksson, and E. Österbacka (2007, March). Nonlinearities in intergenerational earnings mobility: Consequences for cross-country comparisons. Economic Journal 117(519), C72-C92.

Browning, M., M. Gørtz, and S. Leth-Petersen (2013, May). Housing wealth and consumption: A micro panel study. Economic Journal 123(568), 401-428.

Cameron, S. V. and J. J. Heckman (1993, January). The nonequivalence of high school equivalents. Journal of Labor Economics 11(1, Part 1), 1-47.

Cameron, S. V. and J. J. Heckman (2001, June). The dynamics of educational attainment for black, Hispanic, and white males. Journal of Political Economy 109(3), 455-499.

Cameron, S. V. and C. Taber (2004, February). Estimation of educational borrowing constraints using returns to schooling. Journal of Political Economy 112(1), 132-182.

Carneiro, P. and J. J. Heckman (2002, October). The evidence on credit constraints in postsecondary schooling. Economic Journal 112(482), 705-734. 
Carneiro, P., C. Meghir, and M. Parey (2013, January). Maternal education, home environments, and the development of children and adolescents. Journal of the European Economic Association 11 (S1), 123-160.

Cascio, E. U. (2009, May). Do investments in universal early education pay off? Long-term effects of introducing kindergartens into public schools. Working Paper 14951, National Bureau of Economic Research.

Chadwick, L. and G. Solon (2002, March). Intergenerational income mobility among daughters. American Economic Review 92(1), 335-344.

Chetty, R., N. Hendren, P. Kline, and E. Saez (2014). Where is the land of opportunity? The geography of intergenerational mobility in the United States. Quarterly Journal of Economics 129(4), 1553-1623.

Chevalier, A., C. Harmon, V. O'Sullivan, and I. Walker (2013, December). The impact of parental income and education on the schooling of their children. IZA Journal of Labor Economics 2(8), 1-22.

Corak, M. (2006, March). Do poor children become poor adults? Lessons from a cross country comparison of generational earnings mobility. IZA Discussion Paper 1993, Institute for the Study of Labor.

Corak, M. (2013, Summer). Income inequality, equality of opportunity, and intergenerational mobility. Journal of Economic Perspectives 27(3), 79-102.

Cunha, F. and J. J. Heckman (2007, May). The technology of skill formation. American Economic Review 97(2), 31-47. 
Cunha, F. and J. J. Heckman (2008, Fall). Formulating, identifying and estimating the technology of cognitive and noncognitive skill formation. Journal of Human Resources 43(4), $738-782$.

Currie, J. (2001, Spring). Early childhood education programs. Journal of Economic Perspectives 15(2), 213-238.

Currie, J. and D. Thomas (2000, Autumn). School quality and the longer-term effects of Head Start. Journal of Human Resources 35(4), 755-774.

Dahl, M. and T. DeLeire (2008, August). The association between children's earnings and fathers' lifetime earnings: Estimates using administrative data. Discussion Paper 1342-08, Institute for Research on Poverty, University of Winsconsin-Madison.

Datta Gupta, N. and M. Simonsen (2010, February). Non-cognitive child outcomes and universal high quality child care. Journal of Public Economics 94(1-2), 30-43.

Datta Gupta, N. and M. Simonsen (2012, September). The effects of type of non-parental child care on pre-teen skills and risky behavior. Economics Letters 116(3), 622-625.

Davies, J. B., J. Zhang, and J. Zeng (2005, September). Intergenerational mobility under private vs. public education. Scandinavian Journal of Economics 107(3), 399-417.

Edin, P.-A. and R. Topel (1997). Wage policy and restructuring: The Swedish labor market since 1960. In R. B. Freeman, R. Topel, and B. Swedenborg (Eds.), The Welfare State in Transition: Reforming the Swedish Model, Chapter 4, pp. 155-202. Chicago: University of Chicago Press.

Elango, S., A. Hojman, J. L. García, and J. J. Heckman (2016). Early childhood education. 
Forthcoming, in Moffitt, Robert (ed.), Means-Tested Transfer Programs in the United States II. Chicago: University of Chicago Press, 2016.

Eriksson, T., B. Bratsberg, and O. Raaum (2005). Earnings persistence across generations: Transmission through health? Memoradum No. 35, Department of Economics, University of Oslo.

Forslund, A. and A. B. Krueger (1997). An evaluation of the Swedish active labor market policy: New and received wisdom. In R. B. Freeman, R. Topel, and B. Swedenborg (Eds.), The Welfare State in Transition: Reforming the Swedish Model, Chapter 6, pp. 267-298. Chicago: University of Chicago Press.

Fredriksson, P. and R. Topel (2010). Wage determination and employment in Sweden since the early 1990s: Wage formation in a new setting. In R. B. Freeman, B. Swedenborg, and R. H. Topel (Eds.), Reforming the Welfare State: Recovery and Beyond in Sweden, Chapter 3, pp. 83-126. Chicago: University of Chicago Press.

Freeman, R. B., B. Swedenborg, and R. Topel (2010). Introduction. In R. B. Freeman, B. Swedenborg, and R. H. Topel (Eds.), Reforming the Welfare State: Recovery and Beyond in Sweden, pp. 1-23. Chicago: University of Chicago Press.

Gottschalck, A., M. Vornovytskyy, and A. Smith (2013, March). Household wealth and debt in the U.S.: 2000 to 2011. Press release, U.S. Census Bureau, Washington, DC.

Hai, R. and J. J. Heckman (2016). Inequality in human capital and endogenous credit constraints. Under review at Review of Economic Dynamics.

Harmon, C., H. Oosterbeek, and I. Walker (2003). The returns to education: Microeconomics. Journal of Economic Surveys 17(2), 115-155. 
Havnes, T. and M. Mogstad (2011a, December). Money for nothing? Universal child care and maternal employment. Journal of Public Economics 95(11-12), 1455-1465.

Havnes, T. and M. Mogstad (2011b, May). No child left behind: Subsidized child care and children's long-run outcomes. American Economic Journal: Economic Policy 3(2), 97-129.

Heckman, J. J. (2011). The american family in black \& white: A post-racial strategy for improving skills to promote equality. Daedalus 140(2), 70-89.

Heckman, J. J., J. E. Humphries, and T. Kautz (Eds.) (2014). The Myth of Achievement Tests: The GED and the Role of Character in American Life. Chicago: University of Chicago Press.

Heckman, J. J. and S. Mosso (2014, August). The economics of human development and social mobility. Annual Review of Economics 6(1), 689-733.

Heckman, J. J. and Y. Rubinstein (2001, May). The importance of noncognitive skills: Lessons from the GED testing program. American Economic Review 91(2), 145-149.

Heckman, J. J., J. Stixrud, and S. Urzúa (2006, July). The effects of cognitive and noncognitive abilities on labor market outcomes and social behavior. Journal of Labor Economics 24(3), $411-482$.

Hertz, T., T. Jayasundera, P. Piraino, S. Selcuk, N. Smith, and A. Verashchagina (2008, January). The inheritance of educational inequality: International comparisons and fiftyyear trends. B. E. Journal of Economic Analysis \& Policy 7(2), 1-46.

Hussain, M., M. D. Munk, and J. Bonke (2009). Intergenerational earnings mobilities - how sensitive are they to income measures? Journal of Income Distribution 18(3-4), 79-92. 
Jäntti, M., K. Røed, R. Naylor, A. Björklund, B. Bratsberg, O. Raaum, E. Österbacka, and T. Eriksson (2006, January). American exceptionalism in a new light: A comparison of intergenerational earnings mobility in the Nordic countries, the United Kingdom and the United States. IZA Discussion Paper 1938, Institute for the Study of Labor, Bonn.

Jensen, A. S., S. Broström, and O. H. Hansen (2010). Critical perspectives on Danish early childhood education and care: Between the technical and the political. Early Years: An International Research Journal 30(3), 243-254.

Jonassen, A. B. (2013). Disincentive effects of a generous social assistance scheme. SFI Working Paper WP 01:2013, Danish National Centre for Social Research, Copenhagen.

Keane, M. P. and K. I. Wolpin (2001, November). The effect of parental transfers and borrowing constraints on educational attainment. International Economic Review 42(4), 1051-1103.

Krueger, A. B. (2012, January). The rise and consequences of inequality in the United States. Speech given at the Center for American Progress, Washington D.C.

Lochner, L. J. and A. Monge-Naranjo (2012, September). Credit constraints in education. Annual Review of Economics 4, 225-256.

Lochner, L. J. and A. Monge-Naranjo (2016). Student loans and repayment: Theory, evidence and policy. Working Paper 20849, National Bureau of Economic Research.

Machin, S. and K. G. Salvanes (2016, January). Valuing school quality via a school choice reform. Scandinavian Journal of Economics 118(1), 3-24.

Mazumder, B. (2005, May). Fortunate sons: New estimates of intergenerational mobility in the United States using Social Security earnings data. Review of Economics and Statistics 87(2), $235-255$. 
McCombs, J. S., S. N. Kirby, and L. T. Mariano (Eds.) (2009). Ending Social Promotion Without Leaving Children Behind: The Case of New York City. Santa Monica, CA: RAND Corporation.

Munk, M. D., J. Bonke, and M. A. Hussain (2016, March). Intergenerational top income persistence: Denmark half the size of Sweden. Economics Letters 140, 31-33.

Nybom, M. and J. Stuhler (2015, January). Biases in standard measures of intergenerational income dependence. Working Paper 2015:13, Institute for Evaluation of Labour Market and Education Policy, Uppsala, Sweden.

Oreopoulos, P. and K. G. Salvanes (2011, Winter). Priceless: The nonpecuniary benefits of schooling. Journal of Economic Perspectives 25(1), 159-184.

Organisation for Economic Co-operation and Development (2001). Executive summary: Starting strong-early education. Technical report, Organisation for Economic Co-operation and Development, Paris.

Organisation for Economic Co-operation and Development (2004). Learning for tomorrow's world: First results from PISA 2003. Technical report, Organisation for Economic Cooperation and Development, Paris.

Organisation for Economic Co-operation and Development (2006). Executive summary: Starting strong II: Early childhood education and care. Technical report, Organisation for Economic Co-operation and Development, Paris.

Organisation for Economic Co-operation and Development (2014). Education at a glance 2014: OECD indicators. Technical report, Organisation for Economic Co-operation and Development, Paris. 
Pedersen, P. J. and N. Smith (2000, September). Trends in Danish income distribution. LABOUR 14(3), 523-546.

Politiken (2014, November). Rektor: Taxameter sænker barren til eksamen. Website: http://politiken.dk/indland/uddannelse/ECE2465532/rektor-taxameter-saenkerbarren-til-eksamen/.

President Clinton (1998). State of the Union Address.

Produktivitetskommissionen (Productivity Commission) (2014, March). Det handler om velstand og velfærd. Slutrapport (final report), Produktivitetskommissionen, Copenhagen.

Rosen, S. (1997). Public employment, taxes, and the welfare state in Sweden. In R. B. Freeman, R. Topel, and B. Swedenborg (Eds.), The Welfare State in Transition: Reforming the Swedish Model, Chapter 2, pp. 79-108. Chicago: University of Chicago Press.

Sacerdote, B. (2011). Nature and nurture effects on children's outcomes: What have we learned from studies of twins and adoptees? In J. Benhabib, A. Bisin, and M. O. Jackson (Eds.), Handbook of Social Economics, Volume 1A, Chapter 1, pp. 1-30. Amsterdam: Elsevier B. V.

Sanders, B. (2013, July). What can we learn from Denmark? Blog post, Huffington Post.

Simonsen, M. (2010, September). Price of high-quality daycare and female employment. Scandinavian Journal of Economics 112(3), 570-594.

Solon, G. (1992, June). Intergenerational income mobility in the United States. American Economic Review 82(3), 393-408. 
Solon, G. (2002, Summer). Cross-country differences in intergenerational earnings mobility. Journal of Economic Perspectives 16(3), 59-66.

Solon, G. (2004). A model of intergenerational mobility variation over time and place. In M. Corak (Ed.), Generational Income Mobility in North America and Europe, Chapter 2, pp. 38-47. Cambridge: Cambridge University Press.

Statistics Denmark (2016). Net wealth by component and family type. Website, http://statistikbanken.dk/statbank5a/default.asp?w=375 (Accessed 5/6/2016).

Taguma, M., I. Litjens, and K. Makowiecki (2013). Quality matters in early childhood education and care: Sweden. Technical report, Organisation for Economic Co-operation and Development, Paris.

Tiebout, C. M. (1956). A pure theory of local expenditures. The Journal of Political Economy $64(5), 416-424$.

Tranæs, T. (2006). Velfærd og arbejde. In T. Tranæs (Ed.), Skat, Arbejde og Lighed, Chapter 1, pp. 13-32. Copenhagen: Gyldendal.

Trivedi, P. K. and D. M. Zimmer (2007, April). Copula modeling: An introduction for practitioners. Foundations and Trends in Econometrics 1(1), 1-111.

United States Department of Education (1999, May). Taking responsibility for ending social promotion: A guide for educators and state and local leaders. Technical report, United States Department of Education, Washington, DC.

Washington's Blog (2014, November). The American dream has moved to Scandinavia. Website, http://www.washingtonsblog.com/2014/11/american-dream-moved-scandinavia.html. 
Zimmerman, D. J. (1992, June). Regression toward mediocrity in economic stature. American Economic Review 82(3), 409-429. 
A Appendix 


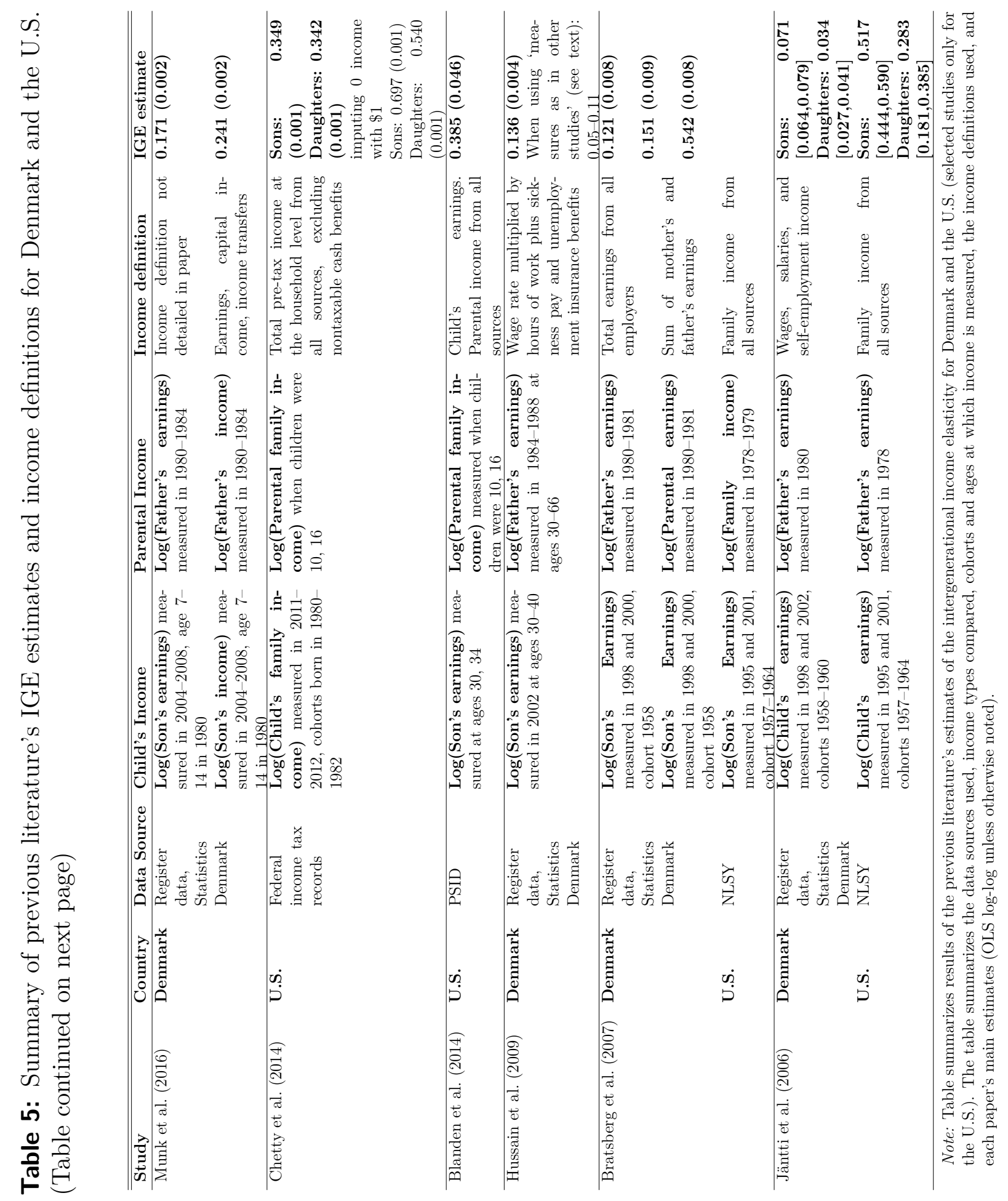




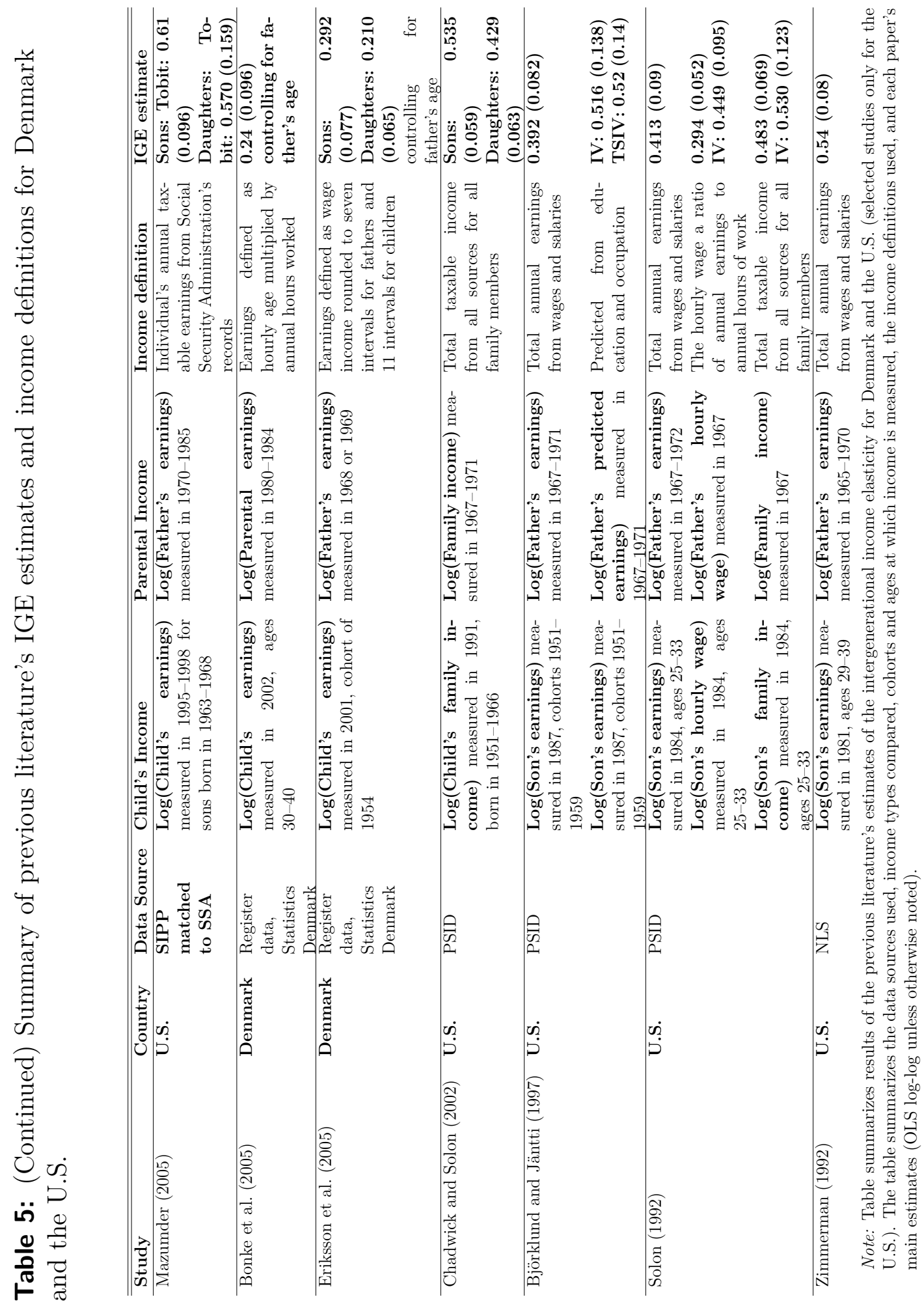


Figure 12: High school completion and college attendance rates, variation across schools and parental characteristics

(a) Average high school completion rates and parental(b) Average college attendance rates and parental gross gross income across schools income across schools
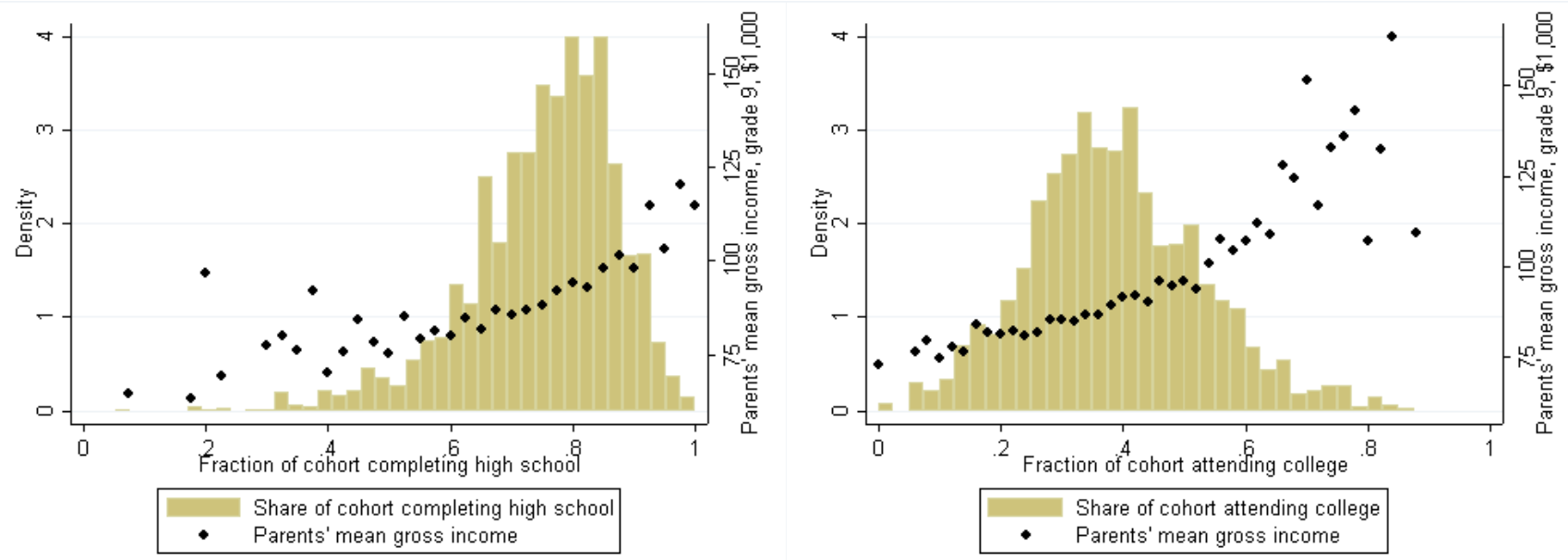

(d) High school completion and college attendance rates (c) High school completion and college attendance ratesacross average highest grade completed of school peers' across average gross income of school peers' parents parents
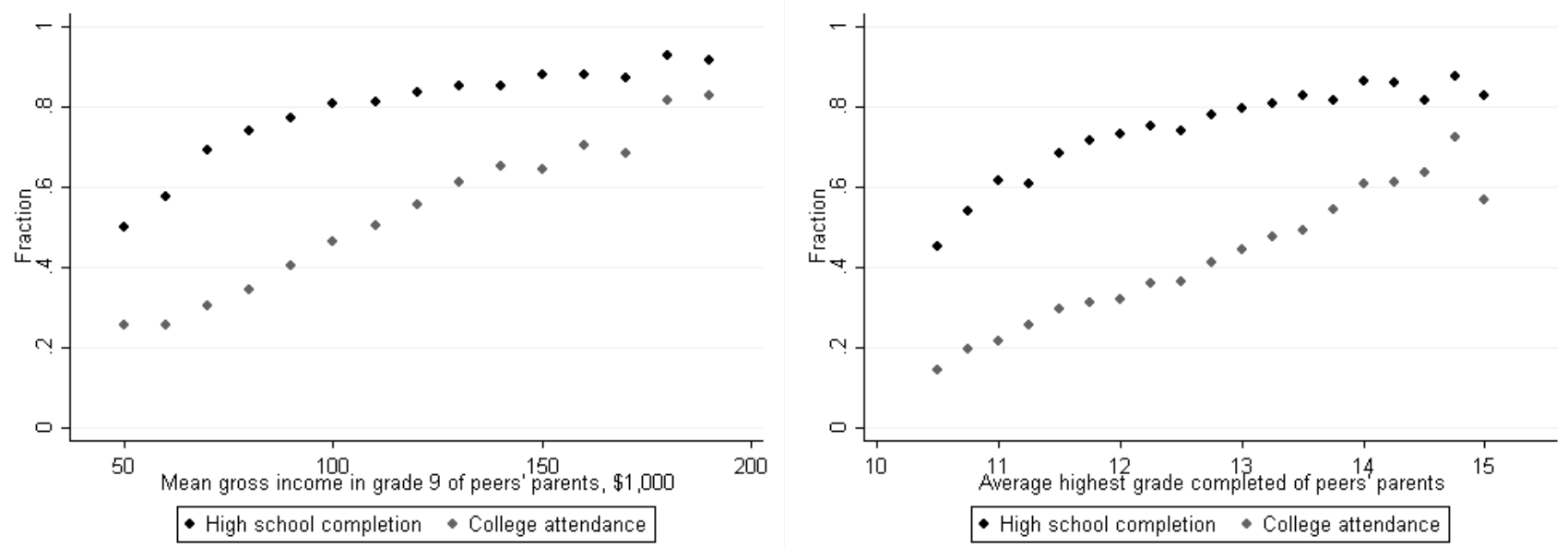

Note: Figures $12 \mathrm{a}$ and $\mathrm{b}$ show distributions of average high school completion and college attendance rates within a school cohort (born in 1987) in the bars and scatterplots of the bin-means of parental gross income in grade 9.

Figures 12, and d show average high school completion and college attendance rates across the mean levels of the income of peers' (students born in 1987 and belonging to the same school and school cohort) parents. All four figures have been constructed using the Danish register data described in Section 3.1 
Figure 13: Test score gaps in Denmark at age 7 and age 12, by parental permanent gross income

(a) Socio-emotional difficulties (SDQ), age 7

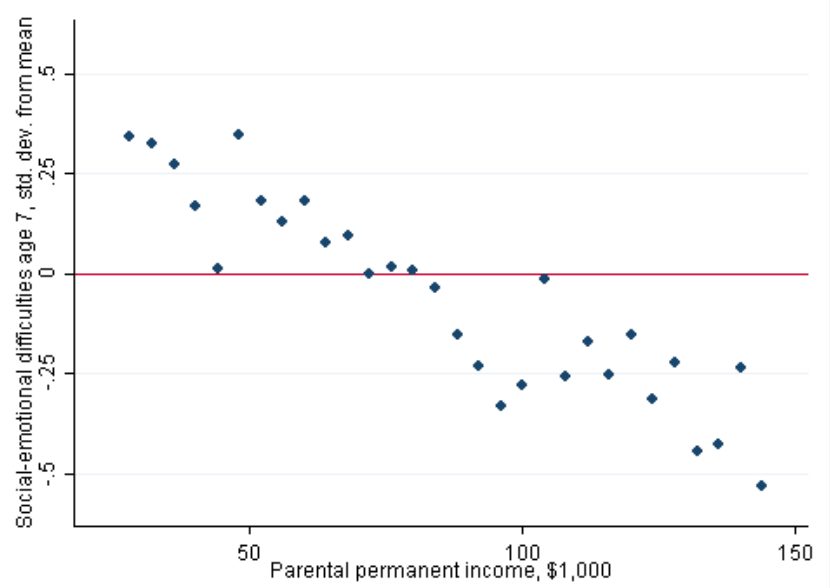

(c) Cognitive test scores, age 12

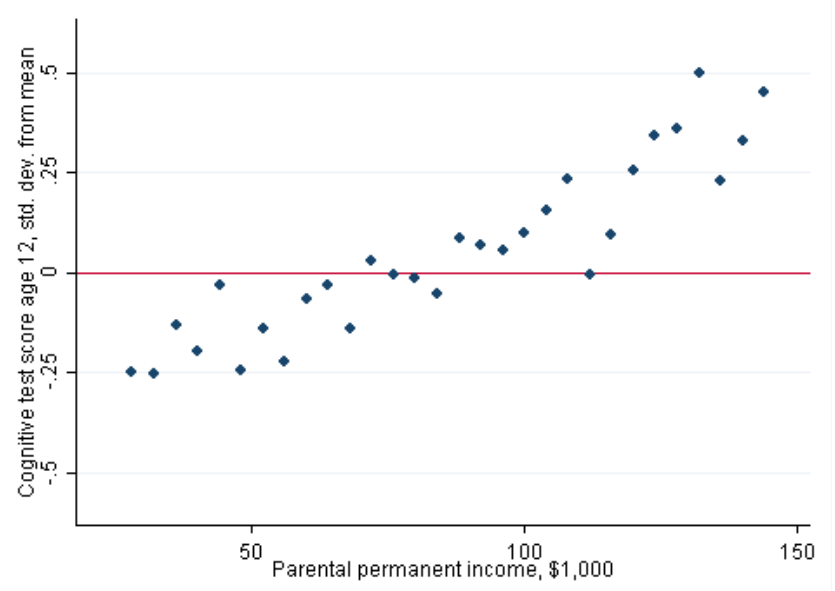

(b) Socio-emotional difficulties (SDQ), age 12

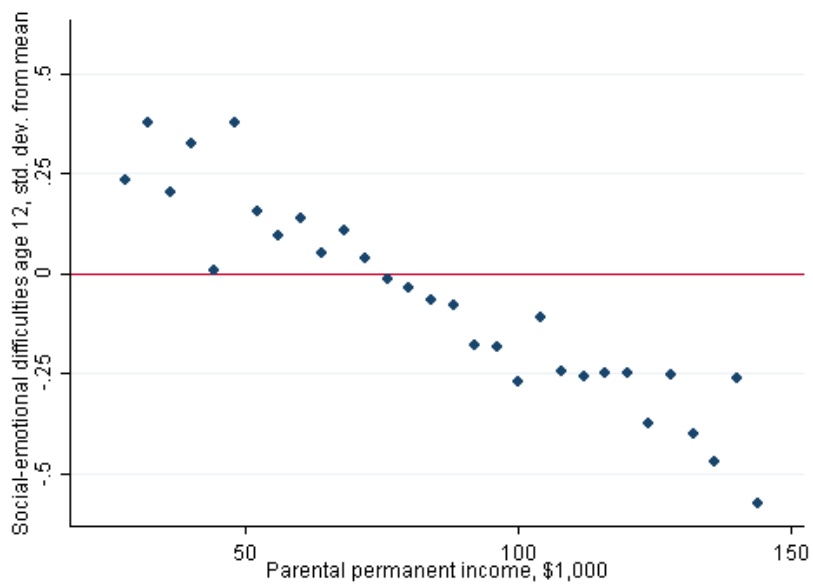

(d) Language test scores, age 12

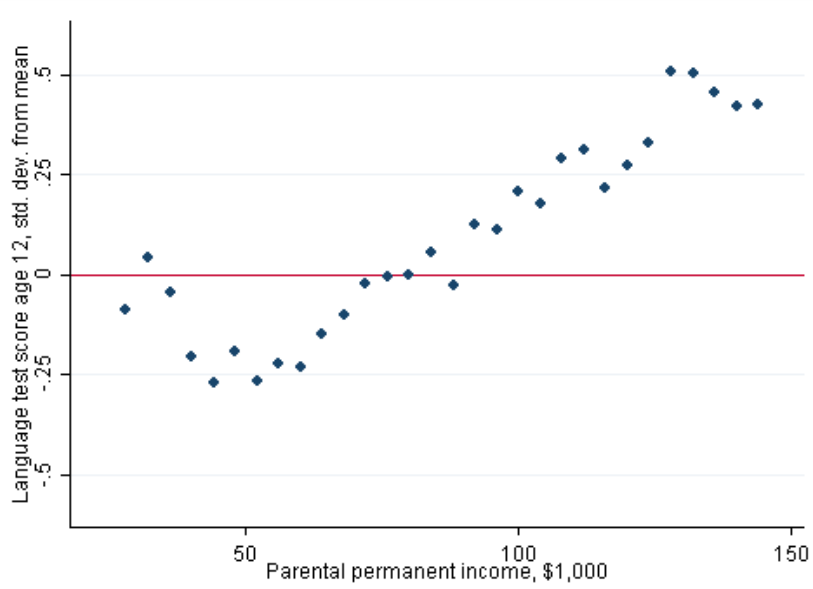

Note: Figure shows deviations of SDQ scores (in figures a and b), CHIPS scores (cognitive test in figure c), and a laguage test score (in figure d) relative to the sample mean by $\$ 4,000$ bins of parental permanent gross income including transfers. Scores have been standardized to mean 0 and standard deviation 1. A higher score of SDQ implies greater socio-emotional difficulties. A higher score in the CHIPS and laguage test implies better cognitive and language skills. Figures have been constructed using Danish register data in combination with the Danish Longitudinal Study of Children (DALSC), see: http://gl.sfi.dk/Default.aspx?AreaID=21 